\title{
Effect of BRAF-mediated PI3K/Akt/mTOR pathway on biological characteristics and chemosensitivity of NSCLC A549/DDP cells
}

\author{
BINGNAN REN, HONGTAO LIU, YUPENG YANG and YUFEI LIAN \\ Department of Pharmacy, Hebei General Hospital, Shijiazhuang, Hebei 050053, P.R. China
}

Received January 28, 2020; Accepted March 9, 2021

DOI: $10.3892 / \mathrm{ol} .2021 .12845$

\begin{abstract}
The present study aimed to explore the biological characteristics of non-small cell lung cancer (NSCLC) cells and the mechanism of chemosensitivity through the role of the PI3K/Akt/mTOR signaling pathway mediated by BRAF gene silencing. Following cell transfection and grouping, an MTT assay detected the activity of NSCLC cells, a scratch wound test assessed the migration ability, flow cytometry using PI staining detected the cell cycle phase, TUNEL and flow cytometry through Annexin V-PI staining assessed the apoptosis, and colony formation was used to detect the sensitivity of lung cancer cells to cisplatin chemotherapy. Furthermore, the relative expression levels of BRAF, PTEN, PI3K, mTOR mRNA were assessed by RT-qPCR, and the protein expression levels of BRAF, PTEN, PI3K, phosphorylated (p)-PI3K, Akt, p-Akt, mTOR, p-mTOR, cisplatin resistance-related enzymes ERCC1 and BRCA1, apoptotic proteins Bax and Bcl-2 were assessed by western blotting. Compared with the control group and NC group, there were differences in decreased BRAF mRNA expression levels in the small interfering (si)BRAF group and siBRAF + IGF-1 group (both $\mathrm{P}<0.05$ ). In addition, compared with the control group, the siBRAF, NVP-BEZ235 and siBRAF + NVP-BEZ235 groups had significant decreased cell viability at 2-6 days, decreased migration ability, shortened proportion of S-phase cells, increased proportion of $\mathrm{G}_{1} / \mathrm{G}_{0}$-phase cells, increased apoptosis rate, decreased number of colony-forming cells, decreased mRNA expression of PI3K, Akt and mTOR, increased PTEN mRNA expression, decreased protein expression levels of PI3K, p-PI3K, Akt, p-Akt, mTOR, p-mTOR, ERCC1, BRCA1 and Bcl-2, and increased protein expression levels of PTEN and Bax (all $\mathrm{P}<0.05$ ); and more obvious trends were revealed in the siBRAF + NVP-BEZ235 group (all $\mathrm{P}<0.05$ ); whereas opposite
\end{abstract}

Correspondence to: Dr Bingnan Ren, Department of Pharmacy, Hebei General Hospital, 348 Heping West Road, Shijiazhuang, Hebei 050053, P.R. China

E-mail: r5p2b2@163.com; renbingnanr6@outlook.com

Key words: BRAF gene, PI3K/Akt/mTOR signaling pathway, non-small cell lung cancer cells, biological characteristics, chemosensitivity results were detected in the siBRAF + IGF-1 group when compared with the siBRAF group and NVP-BEZ235 group (all $\mathrm{P}<0.05$ ). Silencing of BRAF gene expression to inhibit the activation of the PI3K/Akt/mTOR signaling pathway exerted a synergistic effect decreasing cell viability, inhibiting the cell cycle and migration, increasing the apoptosis rate, decreasing the number of colony-forming cells and increasing chemosensitivity of NSCLC. Activation of the PI3K/Akt/mTOR signaling pathway may reverse the role of silencing of BRAF gene expression, providing a potential approach for improving the chemosensitivity of NSCLC. The present study for the first time, to the best of our knowledge, clarified the possible mechanism of NSCLC cell biological characteristic changes and chemosensitivity from the perspective of BRAF gene silencing and PI3K/Akt/mTOR signaling pathway activation, providing a potential reference for suppressing tumor aggravation and improving the therapeutic outcomes of NSCLC at the genetic level.

\section{Introduction}

As the predominant malignant tumor with high incidence worldwide, lung cancer has been reported to be primarily responsible for cancer-related deaths (1). With the improvement of living standards and health awareness of the public, detection and diagnosis techniques of lung cancer have improved in recent years (2). However, the incidence of lung cancer is still rising in both men and women around the world (3). Treatment approaches of lung cancer are constantly improving, however its long-term survival rate has not significantly improved, due to failure of early detection, early treatment and its complexity in pathogenesis $(3,4)$. In addition, non-small cell lung cancer (NSCLC) accounting for $\sim 80-85 \%$ of the total incidence of lung cancer, is primarily diagnosed at an advanced stage with a quite low 5-year survival rate $(5,6)$. Hence, it is necessary to explore the pathogenesis of NSCLC and potential molecular mechanism related to early diagnosis and treatment of this type of cancer. Chemotherapy is an important treatment for local advanced NSCLC (7). Although tumor tissues may shrink or even disappear after chemotherapy, some patients will experience local recurrence or even distant metastasis (8).

In general, the recurrence and metastasis of a tumor is a process involving multiple factors, genes and stages (9). For example, in the process of recurrence and metastasis, cells from the primary tumor proliferate in a large amounts, forming 
new blood vessels and growing rapidly (10). In addition, tumor cells disseminate from the primary site, invade and penetrate the basement membrane, and then invade blood vessels, the lymphatic system or body cavities (11). Furthermore, tumor cells adhere to the capillary wall of the target organ, pass through blood vessels and form a small metastatic mass, which in turn proliferates and produces new blood vessels, forming a secondary tumor of the same type as the primary tumor, resulting in another tumor cell invasion and metastasis $(12,13)$. Tumor recurrence and metastasis enhance the invasion and proliferation of tumor cells (14). Nevertheless, in clinical practice, although clinical stage, tissue type and differentiation degree, invasion depth and lymph node metastasis can partly predict the recurrence and metastasis of patients after treatment $(15,16)$, there remains a shortage of systematic research concerning specific mechanisms of local recurrence and progression of lung cancer after chemotherapy.

In recent years, the molecular diagnosis and targeted treatment of lung cancer provide a new direction for its comprehensive prevention and treatment. Correlation of the expression of special genes with tumor stages and the prognosis of patients has gradually become a major direction of lung cancer research (17). Prior evidence supports that one of the important reasons for the resistance of tumor cells to chemotherapy relates to the abnormal activation or inhibition of intracellular signal transduction pathways (18). For instance, the PI3K/Akt/mTOR signaling pathway has been revealed to be commonly upregulated in multiple cancer cells $(19,20)$. The pathway is regulated by tyrosine kinase receptors, such as epidermal growth factor receptor 1-2 and insulin-like growth factor 1, which are indispensable for maintaining tumor cell proliferation, forming independent clones and distant invasion $(21,22)$. Furthermore, PI3K/Akt/mTOR activation can upregulate the expression of P-glycoprotein, multidrug resistance protein 1 and other drug-resistant proteins, in order to cause resistance to various chemotherapy drugs (23). In addition, the BRAF gene belonging to the RAF gene family, mediates the integration of RAS and MAPK, which have been recognized to regulate cell proliferation, differentiation and apoptosis, and whose mutation and high expression have been reported to be associated with lung cancer (24). However, systematic research is required with respect to the involvement of the BRAF gene and the PI3K/Akt/mTOR signaling pathway in the recurrence and metastasis of lung cancer after chemotherapy, and the specific mechanism of aberrant expression of this pathway as it affects chemotherapy resistance.

Therefore, to explore the possible mechanism of local recurrence and chemosensitivity after chemotherapy for lung cancer, the present study used NSCLC cell lines to explore the biological characteristics of lung cancer cells after chemotherapy, the change of the PI3K/Akt/mTOR pathway by BRAF gene silencing and the chemosensitivity, preliminarily. In addition, our study explored the mechanism involved in improving the chemotherapeutic effect by inhibiting the PI3K/Akt/mTOR pathway.

\section{Materials and methods}

Experimental cells and grouping. The present study used a cisplatin-resistant NSCLC (A549/DDP) cell line, purchased from the Cell Center of the Chinese Academy of Medical
Sciences, which was cultured in a $5 \% \mathrm{CO}_{2}$ cell incubator at $37^{\circ} \mathrm{C}$. Prior to cell transfection, A549/DDP cells were cultured in a culture medium containing $1 \mu \mathrm{g} / \mathrm{ml}$ cisplatin in a routine incubator with saturated humidity and $5 \% \mathrm{CO}_{2}$ at $37^{\circ} \mathrm{C}$. NSCLC cells were designed and divided into a control group (no cell transfection), a negative control (NC) group [transfected with the small interfering (si)RNA NC sequence], a siBRAF group (transfected with a siBRAF plasmid), an NVP-BEZ235 group (a PI3K/Akt/mTOR signaling pathway inhibitor; dual inhibitor of both PI3K and mTOR), a siBRAF + NVP-BEZ235 group (transfected with a siBRAF plasmid combined with the proposed pathway inhibitor), and a siBRAF + IGF-1 group (transfected with a siBRAF plasmid combined with treatment of PI3K/Akt/mTOR signaling pathway agonist, PI3K agonist). The BRAF siRNA sequences for knockdown of BRAF were as follows: Sense, 5'-AGAAUUGGAUCUGGAUCAU-3' and antisense; 5'-AUGAUCCAGAUCCAAUUCU; and the NC siRNA was: Sense, 5'-UUCUCCGAACGUGUCACGUTT-3' and antisense, 5'-TTA AGAGGCUUGCACAGUGCA-3'. When A549/DDP cells grew to the logarithmic growth phase, the cells were digested with $0.25 \%$ trypsin, and the cells were re-suspended with M199 medium supplemented with $10 \%$ fetal bovine serum (Thermo Fisher Scientific, Inc.) at an adjusted density of $11 \times 10^{5}$ cells $/ \mathrm{ml}$, and then inoculated into a 6-well culture plate. When the cells grew to $70 \%$ confluence, the serum-free M199 medium was replaced and transfection was performed following culture for $24 \mathrm{~h}$. An amount of $200 \mu \mathrm{l}$ serum-free Opti-MEM culture medium (Gibco; Thermo Fisher Scientific, Inc.) was added to dilute $5 \mu$ l Lipofectamine 2000 (Invitrogen; Thermo Fisher Scientific, Inc.). Subsequently, $100 \mu \mathrm{l}$ serum-free Opti-MEM culture medium was collected to dilute 100 pmol siRNA or NC siRNA which was to be transfected, followed by separate mixing and reaction at room temperature quietly for $10 \mathrm{~min}$. Then the two solutions were mixed well and incubated at room temperature for $20 \mathrm{~min}$. The original medium was discarded from the 6 -well plate, and Opti-MEM medium was added to the transfection complex in the corresponding cell culture wells. Then, the aforementioned medium was cultured in an incubator with $5 \% \mathrm{CO}_{2}$ at $37^{\circ} \mathrm{C}$ for $18 \mathrm{~h}$, and the prepared cells were collected after $48 \mathrm{~h}$ of transfection after replacement of new complete medium. As for cell treatment, prior to following the tests, cells were treated by cisplatin (Shanghai Baoman Biotechnology Co., Ltd.) at different concentrations $(0.5,1$ and $3 \mu \mathrm{l})$ before grouping for $24 \mathrm{~h}$.

MTT colorimetric assay. MTT colorimetric method was used for determination of cell survival after $20 \mu \mathrm{l}$ of cisplatin treatment for $30 \mathrm{~h}$ of continuous culture. After transfection, A549/DDP cells at the logarithmic growth phase were digested with $0.25 \%$ trypsin to prepare a cell suspension. The cell concentration was adjusted to $2-5 \times 10^{4}$ cells $/ \mathrm{ml}$ and cells were seeded into a 96-well culture plate. Then, $100 \mu \mathrm{l}$ of cell suspension was supplemented per well (the final concentration was $5 \times 10^{4}$ cells/well) for culture in a $5 \% \mathrm{CO}_{2}$ cell incubator at $37^{\circ} \mathrm{C}$ for $48 \mathrm{~h}$. After the cells adhered to the wall for $2 \mathrm{~h}$, the original culture medium was aspirated and discarded. Then, $20 \mu \mathrm{l}(5 \mathrm{mg} / \mu \mathrm{l})$ of MTT solution was added to each well $4 \mathrm{~h}$ before the termination of the culture, followed by continuous incubation in the $5 \% \mathrm{CO}_{2}$ cell incubator at $37^{\circ} \mathrm{C}$ for $4 \mathrm{~h}$. The 
Table I. Comparison of cell cycle phases in each group after transfection by flow cytometric assay.

\begin{tabular}{lccc}
\hline & \multicolumn{3}{c}{ Cell cycle phases } \\
\cline { 2 - 4 } Groups & $\mathrm{G}_{1} / \mathrm{G}_{0}$ & $\mathrm{~S}$ & $\mathrm{G}_{2} / \mathrm{M}$ \\
\hline Control & $48.40 \pm 1.77$ & $39.12 \pm 1.18$ & $12.48 \pm 0.64$ \\
NC & $47.21 \pm 1.45$ & $38.35 \pm 1.32$ & $14.44 \pm 0.36$ \\
siBRAF & $69.41 \pm 1.90^{\mathrm{a}}$ & $21.49 \pm 0.87^{\mathrm{a}}$ & $9.10 \pm 0.17^{\mathrm{a}}$ \\
NVP-BEZ235 & $68.34 \pm 1.72^{\mathrm{a}}$ & $23.51 \pm 0.69^{\mathrm{a}}$ & $8.15 \pm 0.26^{\mathrm{a}}$ \\
siBRAF + NVP-BEZ235 & $86.00 \pm 1.89^{\mathrm{a}, \mathrm{b}}$ & $10.74 \pm 0.71^{\mathrm{a}, \mathrm{b}}$ & $3.26 \pm 0.15^{\mathrm{a}, \mathrm{b}}$ \\
siBRAF + IGF-1 & $45.91 \pm 1.60^{\mathrm{b}}$ & $39.55 \pm 1.20^{\mathrm{b}}$ & $14.54 \pm 0.41^{\mathrm{b}}$ \\
\hline
\end{tabular}

${ }^{a} \mathrm{P}<0.05$, compared with the control group and $\mathrm{NC}$ group, exhibiting statistical difference; ${ }^{b} \mathrm{P}<0.05$, compared with the siBRAF $+\mathrm{NVP}-\mathrm{BEZ} 235$ group, exhibiting statistical difference. NC, negative control; si, small interfering.

culture solution of each well was aspirated, followed by the addition of $150 \mu 110 \%$ DMSO into each well, and shaking with a shaker for $10 \mathrm{~min}$ in order to dissolve the crystal precipitate. Subsequently, the absorbance (OD) of each well was measured with an MTT enzyme-linked immunometric meter (Shanghai Precision Instrument Co., Ltd.) at a wavelength of $490 \mathrm{~nm}$. The cell survival rate was calculated as follows: Cell survival rate $=(\mathrm{OD}$ of the control group - $\mathrm{OD}$ of the experimental group/OD of the control group) $x 100 \%$. The results were expressed by the mean values of the OD of three replicates.

Wound healing assay. After $48 \mathrm{~h}$ of transfection, cells at the logarithmic growth phase in each group were obtained for inoculation in a $35-\mathrm{mm}$ dish at a cell density of $5 \times 10^{4}$ cells $/ \mathrm{ml}$. After the cell confluence was synthesized into a single layer, a 1-mm wide scratch was carefully made (across the well; with at least 5 lines in each well) in the center of the monolayer cells at the bottom of the culture dish with a sterilized $10-\mu 1$ pipette tip, followed by washing 3 times with PBS after discarding the culture medium to wash off the floating cells and serum. Images of the cells were captured under an inverted fluorescence microscope (x200 magnification; Olympus Corporation). Then, further routine culture was carried out by changing to a fresh serum-free DMEM culture medium for $24 \mathrm{~h}$ of incubation. Subsequently, PBS was used to wash the floating cells and cell migration of the experimental group was observed using inverted fluorescence microscope (x200 magnification; Olympus Corporation). The control group consisted of the non-transfected cells. After $24 \mathrm{~h}$ of culture, ImageJ software (v1.48; National Institutes of Health) was used to measure the area of the wound to obtain the mean migration distance, with 5 repeats for each well to measure the average and three replicates for each group. The migration rate was calculated according to the formula: Mean migration distance of the experimental group/mean migration distance of the control group x $100 \%$.

Flow cytometry using PI staining. Cells after $48 \mathrm{~h}$ of transfection were washed 3 times with cold PBS, centrifuged $(\sim 1,100 \mathrm{x} \mathrm{g}$ for $5 \mathrm{~min}$ at room temperature) to discard the supernatant, and then re-suspended with PBS to prepare a cell suspension. The cell concentration was adjusted to $\sim 1 \times 10^{7}$ cells $/ \mathrm{ml}$, followed by the addition of $2 \mathrm{ml}$ of $75 \%$ ethanol pre-cooled at $-20^{\circ} \mathrm{C}$ to fix the cells, shaking and mixing well, sealing with a sealing film, and fixation at $4^{\circ} \mathrm{C}$ for over $12 \mathrm{~h}$. Before detection on the flow cytometer, the supernatant was washed twice with PBS, and $200 \mu \mathrm{l}$ cell suspension was added to RNase A to culture in the dark. After $30 \mathrm{~min}$ in a water bath at $37^{\circ} \mathrm{C}$, the RNA was digested and removed, and then $1.5 \mathrm{ml}$ of staining solution containing propidium iodide (PI; Sigma-Aldrich; Merck KGaA) was added to the supernatant for $30 \mathrm{~min}$ at $4^{\circ} \mathrm{C}$. The sample was filtered using a 300-mesh nylon mesh, and mixed well before flow cytometry (Gallios; Beckman Coulter, Inc.). The cell cycle was determined according to the DNA content labeled by PI.

TUNEL detection. After $48 \mathrm{~h}$ of transfection, the cells were inoculated in a plate/dish that contained DMEM medium and cultured at $37^{\circ} \mathrm{C}$ for $24 \mathrm{~h}$, followed by the adjustment of cell density at $5 \times 10^{6}$ cells $/ \mathrm{ml}$. Then, the cells were fixed at room temperature for $10 \mathrm{~min}$ with $4 \%$ neutral formaldehyde, and $100 \mu \mathrm{l}$ cell suspension was dripped on the slide, dried, and washed twice with PBS (5 min each time). Subsequently, PBS containing $2 \% \mathrm{H}_{2} \mathrm{O}_{2}$ was added, and reacted at room temperature for $5 \mathrm{~min}$, followed by PBS washing two times (5 min each time). Excess liquid was removed by filter paper. The reaction solution was prepared with the addition of $5 \mu 1$ TdT enzyme reaction solution (Amyjet Scientific, Inc.), $45 \mu 1$ fluorescence-labeled solution (Beyotime Biotechnology) and $50 \mu 1$ TUNEL (Beyotime Biotechnology), in a total volume of $100 \mu \mathrm{l}$. The solution was prepared when it was required for use to avoid cryopreservation. When the solution was prepared, it was added to culture cells at a constant temperature of $37^{\circ} \mathrm{C}$ in the dark for $60 \mathrm{~min}$. A negative staining control was set with the addition of TdT enzyme-free reaction solution, with other processing steps and conditions similar to those aforementioned. Then, PBS washing was repeated twice (5 min each time). Subsequently, the cells were re-stained with the addition of DAPI at room temperature for $5 \mathrm{~min}$, followed by another three washes with PBS (5 min each time) and the reaction was terminated by adding a drop of anti-fade mounting medium on the sample. For the determination of the results it was observed that the apoptotic cell nucleus was varying degrees of brown, the nuclear membrane and cell membrane were intact, and the non-apoptotic cells were stained blue. The number of cells was counted under a light microscope (magnification, x400; 
Table II. Comparison of colony-forming number of cells of each group after transfection as determined by colony formation assay.

\begin{tabular}{lccc}
\hline & \multicolumn{3}{c}{ Concentrations $(\mu 1)$} \\
\cline { 2 - 4 } Groups & 0.5 & 1 & 3 \\
\hline Control & $66.56 \pm 4.27$ & $35.72 \pm 4.12$ & $11.08 \pm 1.85$ \\
NC & $63.07 \pm 4.13$ & $32.00 \pm 3.89$ & $9.86 \pm 1.68$ \\
siBRAF & $17.06 \pm 2.65^{\mathrm{a}}$ & $4.67 \pm 0.48^{\mathrm{a}}$ & $0^{\mathrm{a}}$ \\
NVP-BEZ235 & $16.45 \pm 2.08^{\mathrm{a}}$ & $4.55 \pm 0.32^{\mathrm{a}}$ & $0^{\mathrm{a}}$ \\
siBRAF + NVP-BEZ235 & $4.33 \pm 0.37^{\mathrm{a}, \mathrm{b}}$ & $0^{\mathrm{a}, \mathrm{b}}$ & $0^{\mathrm{a}}$ \\
siBRAF + IGF-1 & $59.98 \pm 3.76^{\mathrm{b}}$ & $28.65 \pm 3.42^{\mathrm{b}}$ & $8.27 \pm 1.47^{\mathrm{b}}$ \\
\hline
\end{tabular}

${ }^{a} \mathrm{P}<0.05$, compared with the control group and NC group, exhibiting statistical difference; ${ }^{\mathrm{b}} \mathrm{P}<0.05$, compared with the siBRAF $+\mathrm{NVP}-\mathrm{BEZ} 235$ group, exhibiting statistical difference. NC, negative control; si, small interfering.

Shanghai Dianying Optical Instrument Co., Ltd), and 5 visual fields were randomly selected for each slide that was processed as described in the aforementioned steps. Apoptosis was observed under the light microscope, and the percentage of apoptotic cells was calculated based on the formula: Apoptosis rate $(\%)=($ number of apoptotic cells/total cells) $\times 100 \%$.

Flow cytometry using Annexin V-PI staining. After $48 \mathrm{~h}$ of transfection, the cells were collected and the cell culture medium was removed. At room temperature, the cells were washed twice with PBS, trypsin was added into the culture plate for $24 \mathrm{~min}$, and $2 \mathrm{ml}$ of culture medium without penicillin-streptomycin and serum was added to terminate digestion. The digested cells were aspirated from a 6-well plate into a 10-ml centrifuge tube for centrifugation at $\sim 1,100 \mathrm{x}$ for $6 \mathrm{~min}$. The supernatant was discarded and $1 \mathrm{ml}$ of pre-cooled PBS was added to prepare the cell suspension. Following another centrifugation and preparation of the cell suspension, samples were centrifuged at $\sim 1,100 \mathrm{x} g$ for $6 \mathrm{~min}$. After discarding the supernatant, $100 \mu 11 \mathrm{X}$ Binding buffer was added to suspend the cells. With the addition of $10 \mu \mathrm{l}$ Annexin V and PI subsequently in $100 \mu \mathrm{l}$ cell suspension, cells were incubated at room temperature in the dark for $15 \mathrm{~min}$, followed by another addition of $100 \mu \mathrm{l}$ pre-cooled $1 \mathrm{X}$ binding buffer. The apoptotic rate was quantitatively analyzed by FACSCalibur flow cytometer with apoptosis software Cellquest Pro (both from BD Biosciences).

Colony formation assay. After transfection, cells in the logarithmic phase were obtained from each group, followed by digestion and dispersion of the cell suspension with trypsin, and the cell density was adjusted to 500 cells $/ \mathrm{ml}$. Then, $1 \mathrm{ml}$ of culture medium and $1 \mathrm{ml}$ of diluted cell suspension were added into the 6-well culture plate, respectively, followed by the addition and treatment with cisplatin at different concentrations of $0.5,1.0$ and $3.0 \mu \mathrm{l} / \mathrm{ml}$, with three replicates in each group. Subsequently, the mixture in the wells was cultured in an incubator of $5 \% \mathrm{CO}_{2}$ at $37^{\circ} \mathrm{C}$. Then, the culture medium was replaced every 3 days, and discarded 14 days later. After washing 3 times with PBS, the cells were fixed with $4 \%$ formaldehyde at $37^{\circ} \mathrm{C}$ for $15 \mathrm{~min}$, followed by $0.1 \%$ crystal violet staining at $37^{\circ} \mathrm{C}$ for $15 \mathrm{~min}$. In the next step, the number of colonies with $>50$ cells was counted under an inverted fluorescence microscope (x200 magnification; Olympus Corporation), and finally the colony formation rate was obtained in accordance with the following formula: Colony forming rate $(\%)=$ number of colonies/total number of cultured cells x $100 \%$.

Reverse transcription-quantitative (RT-q)PCR. After transfection, the cells of each group in logarithmic phase were digested by trypsin, and the cell density was adjusted to $1 \times 10^{7}$ cells $/ \mathrm{ml}$. The cell suspension was obtained and centrifuged at $\sim 1,100 \mathrm{x} \mathrm{g}$ for $5 \mathrm{~min}$ at room temperature to collect the cell precipitation. TRIzol (Invitrogen; Thermo Fisher Scientific, Inc.) was used to extract total RNA of each group of cells cultured for $24 \mathrm{~h}$ after transfection. The absorbance values at wavelengths of 260 and $280 \mathrm{~nm}$ of the total RNA were measured by Nano-Drop ND-1000 spectrophotometry, and the $\mathrm{OD}_{260} / \mathrm{OD}_{280}$ ratio was calculated to verify the purity and meet the requirement (ratio >1.80). Concurrently, the RNA integrity was measured by $1 \%$ agarose gel electrophoresis. The bands at 28, 18 and $5 \mathrm{sec}$ were clearly displayed under ultraviolet light, indicating that RNA was not degraded. According to the protocol of the related experimental kit, a reverse transcription reaction was carried out on a PCR amplification apparatus to synthesize the cDNA template. The primers were all synthesized by Beijing Genetics Institute Co., Ltd. The reverse transcription system was $20 \mu \mathrm{l}$, which was carried out according to the instructions of EasyScript First-Strand cDNA Synthesis SuperMix (Invitrogen; Thermo Fisher Scientific, Inc.). Real-time fluorescence quantitative PCR was used to calculate the volume ratio of the amplification product of the target gene to the internal reference gene for the measurement of the relative expression of the target gene, with $\beta$-actin as the internal reference. According to the instructions of the SYBR ${ }^{\circledR}$ Premix Ex Taq ${ }^{\mathrm{TM}}$ II kit (Takara Bio, Inc.), fluorescence quantitative PCR was carried out. The reaction system was $25 \mu \mathrm{l}$, including 10X PCR buffer, $1 \mu \mathrm{l}$ cDNA template, $1.7 \mu 125 \mathrm{mM}$ $\mathrm{MgCl}_{2}, 0.5 \mu \mathrm{l}$ of upstream and downstream primers of the target gene, 1 unit of Taq DNA polymerase, $10 \mathrm{mM}$ dNTPs, and sterilized deionized water to supplement the volume. The real-time quantitative PCR experiment was carried out 
using 7500 Real-Time PCR system from ABI (Thermo Fisher Scientific, Inc.). The reaction conditions were as follows: Pre-denaturation at $95^{\circ} \mathrm{C}$ for $5 \mathrm{~min}$, denaturation at $95^{\circ} \mathrm{C}$ for $30 \mathrm{sec}$, annealing at $58^{\circ} \mathrm{C}$ for $30 \mathrm{sec}$ (the aforementioned steps were repeated for 35 cycles under the described conditions), extension at $72^{\circ} \mathrm{C}$ for $1 \mathrm{~min}$, and finally extension at $72^{\circ} \mathrm{C}$ for $10 \mathrm{~min}$. The gene expression levels of BRAF (upstream, 5'-TCA TAATGCTTGCTCTGATAGGA-3' and downstream, 5'-GGC CAAAAATTTAATCAGTGGA-3'); PTEN (upstream, 5'-ACC AGGACCAGAGGAAACCT-3' and downstream, 5'-GCTAGC CTCTGGATTTGACG-3'); PI3K (upstream, 5'-ATGCCAGAA AGGAGAATG-3' and downstream, 5'-TGTTGGACTCAG CAATAC-3'); and mTOR (upstream, 5'-GGATGGCAACTAC AGAATCACA-3' and downstream, 5'-TCACACCCATGACGA ACAT-3'); were then detected with GAPDH (upstream, 5'-ATC ACTGCCACCCAGAAG-3' and downstream, 5'-TCCACGACG GACACATTG-3') as the reference gene. The $2^{-\Delta \Delta \mathrm{Cq}}$ method (25) was used for quantitative analysis, with the following formula: $\Delta \Delta \mathrm{Cq}=\Delta \mathrm{Cq}_{\text {experimental group }}-\Delta \mathrm{Cq}$ Control group .

Western blotting. RIPA lysis buffer (Beyotime Biotechnology) was used to lyse protein. A549/DDP cells were collected and cultured for $24 \mathrm{~h}$ after centrifugation at $450 \mathrm{x} \mathrm{g}$ at $4^{\circ} \mathrm{C}$ for 5 min, washed with PBS and re-suspended. The supernatant was collected after another centrifugation and added to the lysate mixture according to the ratio of $1 \mathrm{ml}$ per $10^{7}$ cells. After an ice bath at $4^{\circ} \mathrm{C}$ for $5 \mathrm{~min}$, the supernatant was centrifuged at $\sim 13,400 \mathrm{x}$ g at $4^{\circ} \mathrm{C}$ for $15 \mathrm{~min}$. The supernatant was then transferred to another centrifuge tube and stored at $-80^{\circ} \mathrm{C}$ (i.e. total protein of cells). Bicinchoninic acid (BCA) working solution was prepared according to the ratio of sample:BCA working solution (1:8), the protein standard was diluted, followed by the addition of $20 \mu \mathrm{l}$ of diluted protein sample into the 96 -well plate standard well, with $200 \mu \mathrm{l}$ of BCA working solution into each well, and then the sample protein concentration was calculated by measuring the absorbance value at a wavelength of $562 \mathrm{~nm}$ with a microplate reader. Subsequently, $30 \mu \mathrm{g}$ of total cell protein was separated by $10 \%$ SDS-PAGE, which was stopped when bromophenol blue was close to $1 \mathrm{~cm}$ from the rubber bottom and then, it was transferred to a PVDF membrane using a wet method, with 5\% skimmed milk powder used to seal for $1 \mathrm{~h}$ on the shaker, followed by washing 3 times with TBST (5 min/time). Then, the primary antibodies of BRAF (product code ab33899; 1:5,000), PTEN (product code ab267787; 1:1,000), PI3K (product code ab32089; 1:1,000), phosphorylated (p)-PI3K (product code ab278545; 1:1,000), mTOR (product code ab32028; 1:2,000), p-mTOR (product code ab109268; 1:5,000), cisplatin resistance-related enzymes ERCC1 (product code ab129267; 1:2,000) and BRCA1 (ab191042; 1:1,000), Bax (product code ab32503; 1:2,000), Bcl-2 (ab32124; 1:1,000) and GAPDH (product code ab8245; 1:10,000; all from Abcam) were added and incubated overnight at $4^{\circ} \mathrm{C}$, followed by washing with TBST (three times, 5 min each time). Subsequently, the secondary antibody, HRP-labeled goat anti-rabbit IgG antibody (product code ab190495; 1:1,000; Abcam) was added and incubated by shaking at room temperature for $2 \mathrm{~h}$, followed by another three washes with TBST (5 min/each time). The reference gene was GAPDH. Finally, the sensitized electrogenerated chemiluminescence (ECL; Amersham; Cytiva) was used for development. The optical density values of the target protein

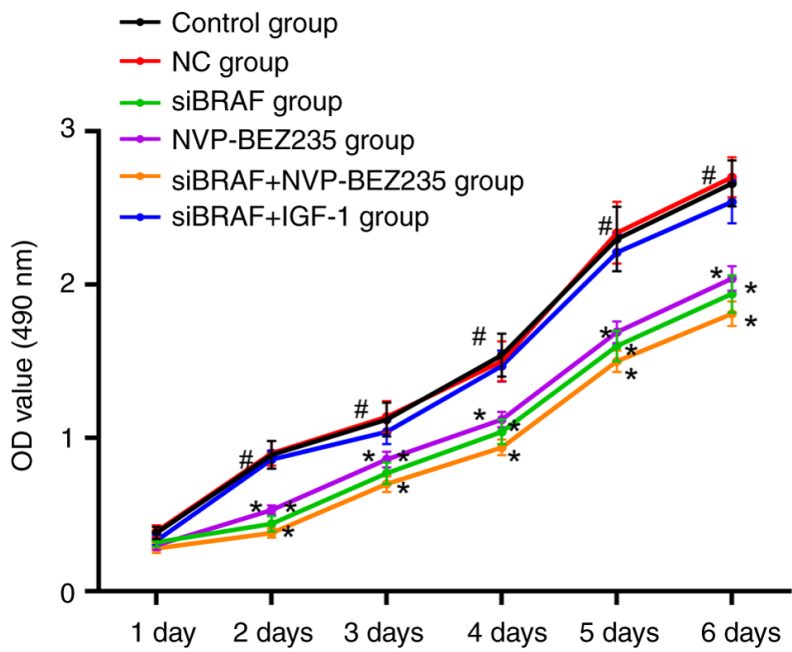

Figure 1. Comparison of cell viability expressed as the OD value in each group after transfection by MTT colorimetric assay. The data were measured and expressed by mean \pm standard deviation. The comparison between the two groups was performed by unpaired t-test, and the comparison between multiple groups was performed by one-way ANOVA. The cell experiment was repeated three times. ${ }^{*} \mathrm{P}<0.05$, compared with the control group and $\mathrm{NC}$ group at the same time-point, revealing statistical difference; ${ }^{\prime} \mathrm{P}<0.05$, compared with the siBRAF + NVP-BEZ235 group at the same time-point, revealing statistical difference. $\mathrm{NC}$, negative control; si, small interfering.

bands and internal reference were measured by ImageJ image analysis software (v1.48), with the corresponding ratio reflecting the relative expression of the target protein.

Statistical analysis. SPSS 21.0 software package (IBM Corp.) was used to analyze the data and calculate the mean value \pm standard deviation (SD). All experiments were repeated at least three times. Following the identification of the normal distribution (Kolmogorov-Smirnov test) and homogeneous nature (Homogeneity of variance test) of the data, t-tests were used for data analysis between groups; one-way analysis of variance (ANOVA) was used for multiple data analysis. Tukey's post hoc test was performed to obtain P-values and adequately assess differences to determine significance following one-way ANOVA. $\mathrm{P}<0.05$ was considered to indicate a statistically significant difference.

\section{Results}

Comparison of cell viability in each group after transfection. There was no difference in cell viability between the control group and NC group at day $1(\mathrm{P}>0.05)$. Compared with the NC group, no obvious change was revealed in cell activity in each group at day 1 , without the estimation of obvious statistical differences (all P>0.05); at 2-6 days, cell viability of the siBRAF group, NVP-BEZ235 group and siBRAF + NVP-BEZ235 group was significantly decreased (all $\mathrm{P}<0.05$ ); while no obvious difference was found with the siBRAF + IGF-1 group (all P>0.05). In addition, there was no significant difference in cell viability between the siBRAF group and NVP-BEZ235 group at 2-6 days (all $\mathrm{P}>0.05$ ); while the cell viability of cancer cells in the siBRAF + IGF-1 group was significantly increased compared with siBRAF + NVP-BEZ235 group (all P<0.05) (Fig. 1). 

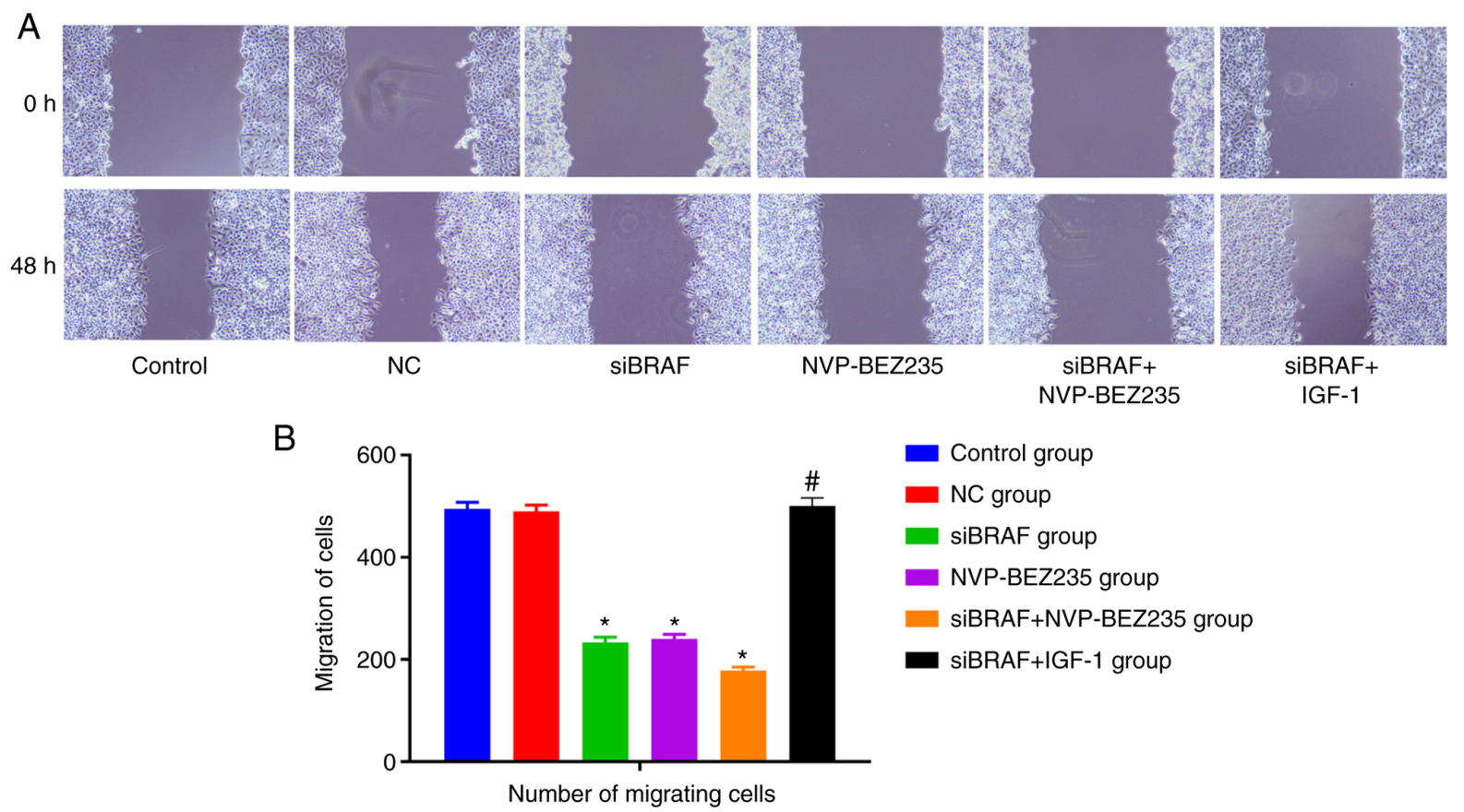

Figure 2. Comparison of cell migration ability expressed as the migrating number of cells and cell scratch distance in each group after transfection by scratch test. (A) Experimental images in each transfection group using the scratch test at $0 \mathrm{~h}$ (as the control) and $48 \mathrm{~h}$ respectively. (B) Comparison of the migration distance in each group. The data were measured and expressed by the mean \pm standard deviation. The comparison between the two groups was performed by unpaired t-test, and the comparison between multiple groups was performed by one-way ANOVA. The cell experiment was repeated three times. ${ }^{*}<0.05$, compared with the control group and NC group, revealing statistical difference; ${ }^{\text {P }}<0.05$, compared with the siBRAF $+\mathrm{NVP}-\mathrm{BEZ} 235$ group, showing statistical difference. NC, negative control; si, small interfering.

Comparison of cell migration in each group after transfection. Compared with the control group, no significant change was detected in migration ability in the NC group, exhibiting no statistical difference $(\mathrm{P}>0.05)$. The migration ability of cancer cells was significantly decreased in the siBRAF group, NVP-BEZ235 group and siBRAF + NVP-BEZ235 group when compared with the NC group (all $\mathrm{P}<0.05)$; while it was evidently increased in the siBRAF + IGF-1 group when compared with the siBRAF + NVP-BEZ235 group, with a statistical difference $(\mathrm{P}<0.05)$, yet no difference was found when compared with that in the NC group ( $\mathrm{P}>0.05)$. There was no significant difference in cell migration between the siBRAF group and NVP-BEZ235 group (P>0.05) (Fig. 2).

Comparison of cell cycle phases in each group after transfection. Compared with the control group, the NC group had no significant difference in the distribution of the cell cycle in the $S$ phase, $G_{2} / M$ phase and $G_{1} / G_{0}$ phase $(P>0.05)$. The proportion of cells in the $S$ phase and $G_{2} / M$ phase in the siBRAF group, NVP-BEZ235 group and siBRAF + NVP-BEZ235 group was decreased, and the proportion of cells in the $G_{1} / G_{0}$ phase was increased, with statistical differences. These trends were more evident in the siBRAF + NVP-BEZ235 group compared with the siBRAF group and NVP-BEZ235 group (all $\mathrm{P}<0.05$ ). In addition, in the siBRAF + IGF-1 group, the proportion of cells in the $S$ phase increased but the proportion of $G_{1} / G_{0}$-phase cells decreased when compared with siBRAF + NVP-BEZ235 group (all $\mathrm{P}<0.05$ ), with no statistically significant difference in the $G_{2} / M$ phase $(P>0.05)$. However, no significant difference was found in the $S, G_{2} / M$ and $G_{1} / G_{0}$ phases between the
siBRAF group and NVP-BEZ235 group, and between the $\mathrm{NC}$ group and the siBRAF + IGF-1 group ( $\mathrm{P}>0.05)$ (Fig. 3; Table I).

Comparison of the apoptosis rate in each group after transfection. The apoptosis of cancer cells in each group after transfection under light microscope by TUNEL assay is presented in Fig. 4. According to the statistical analysis results of the apoptosis rate, there was no significant difference between $\mathrm{NC}$ group and control group $(\mathrm{P}>0.05)$. Compared with $\mathrm{NC}$ group and control group, the apoptosis rate was significantly increased in the siBRAF group and NVP-BEZ235 group, and was especially higher in the siBRAF + NVP-BEZ235 group compared with in siBRAF group and NVP-BEZ235 group (all $\mathrm{P}<0.05)$. Furthermore, no significant difference was found in the apoptosis rate in the siBRAF + IGF-1 group when compared with the NC group and control group; while there was a decreased trend of the rate in the siBRAF + IGF-1 group when compared with siBRAF + NVP-BEZ235 group (all $\mathrm{P}<0.05)$. In addition, no significant difference was revealed in the apoptosis rate between the siBRAF group and NVP-BEZ235 group, and between the NC group and siBRAF + IGF-1 group (all P>0.05).

The apoptosis of cancer cells in each group after transfection was detected by flow cytometry and is presented in Fig. 5. Consistent with the results of the TUNEL assay, it was revealed that there was no difference in the cell apoptosis rate among the control group, NC group and siBRAF + IGF-1 group (both $\mathrm{P}>0.05$ ), which, however, was increased in the siBRAF group and NVP-BEZ235 group, and more markedly increased in the siBRAF + NVP-BEZ235 group, but decreased in siBRAF + IGF-1 group (all $\mathrm{P}>0.05$ ). 

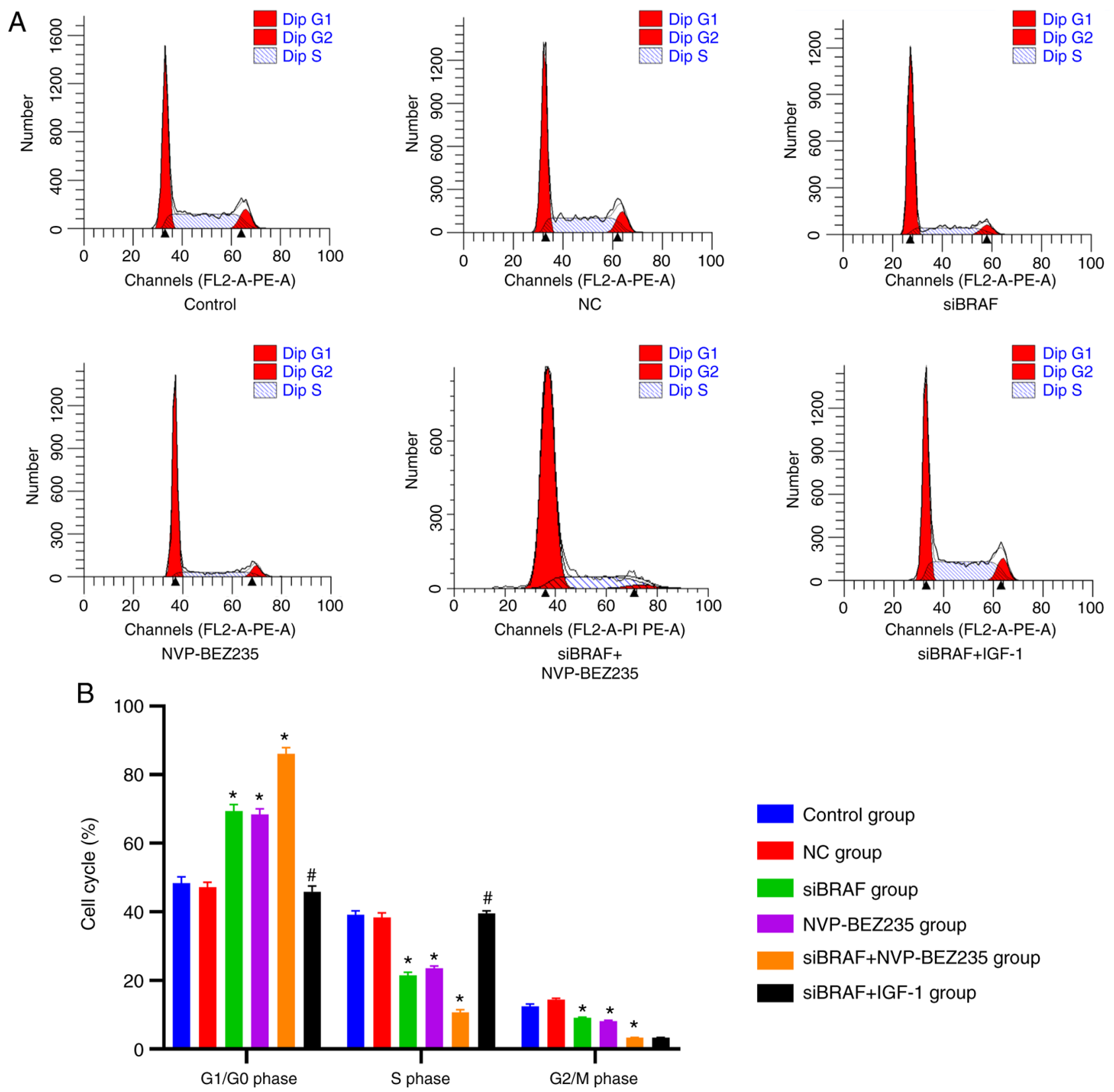

Figure 3. Comparison of cell cycle phases in each group after transfection by flow cytometry using PI staining. (A) The distribution of the cell cycle in each phase in each group. (B) Histogram of the cell cycle distribution in each group expressed as the percentage (\%). The data were measured and expressed as the mean \pm standard deviation. The comparison between the two groups was performed by unpaired t-test, and the comparison between multiple groups was performed by one-way ANOVA. The cell experiment was repeated three times. ${ }^{*} \mathrm{P}<0.05$, compared with the control group and $\mathrm{NC}$ group, revealing statistical difference; ${ }^{\#} \mathrm{P}<0.05$, compared with the siBRAF + NVP-BEZ235 group, showing statistical difference. NC, negative control; si, small interfering.

Comparison of the colony-forming number of cells of each group after transfection. Compared with the control group, there was no significant difference in the number of colony-forming cells in the NC group $(\mathrm{P}>0.05)$. Compared with the NC group, the number of colony-forming cells in the siBRAF group, NVP-BEZ235 group and siBRAF + NVP-BEZ235 group was significantly decreased, and was especially evident in the siBRAF + NVP-BEZ235 group than that in the siBRAF group and NVP-BEZ235 group, with obvious statistical difference (all $\mathrm{P}<0.05$ ); whereas the number of colony-forming cells was increased in the siBRAF + IGF-1 group when compared with siBRAF + NVP-BEZ235 group, with significant difference
$(\mathrm{P}<0.05)$. However, there was no obvious difference in the number of colony-forming cells between the siBRAF group and NVP-BEZ235 group, and between the NC group and siBRAF + IGF-1 group (all P>0.05). Detailed results are presented in Fig. 6 and Table II.

Comparison of mRNA expression levels in each group after transfection. There was no difference in the mRNA expression levels of the detected indexes between the control group and NC group $(\mathrm{P}>0.05)$. No significant difference was observed in BRAF mRNA expression between NVP-BEZ235 group and $\mathrm{NC}$ group $(\mathrm{P}>0.05)$; while it was decreased in the siBRAF group, siBRAF + NVP-BEZ235 group and siBRAF + IGF-1 group 


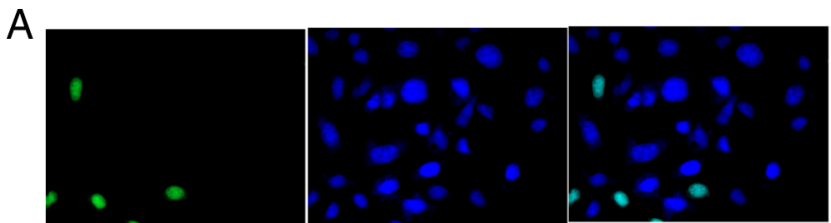

Control

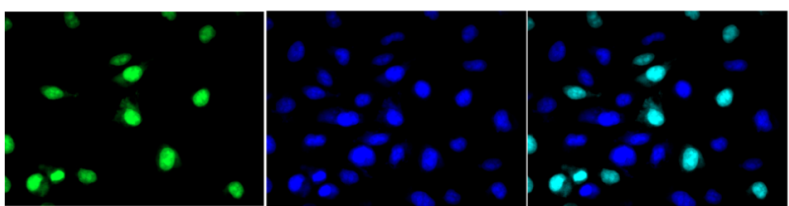

SiBRAF

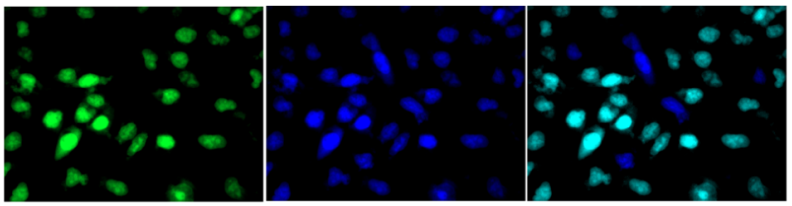

SiBRAF+NVP-BEZ235

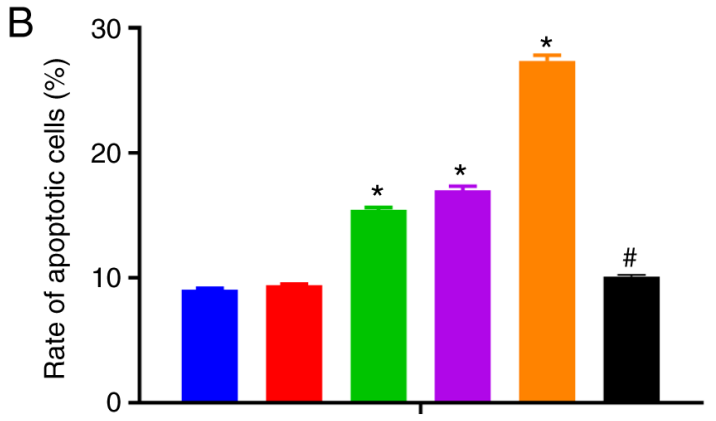

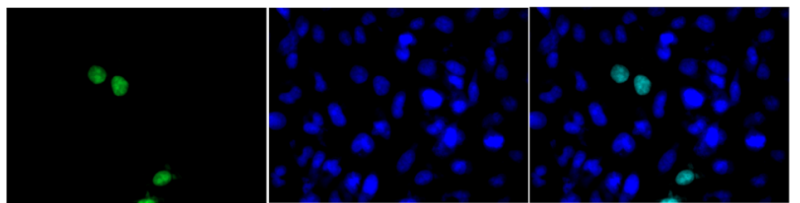

NC

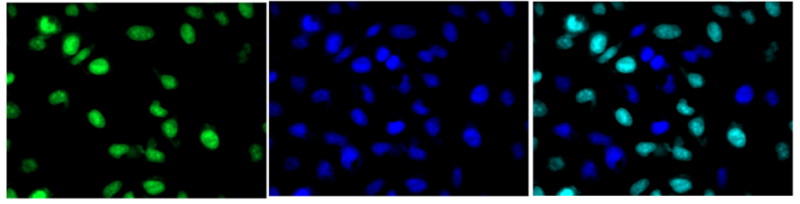

NVP-BEZ235

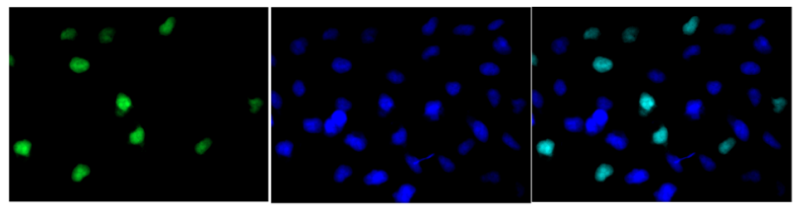

SiBRAF+|GF-1

(FITC/DAPI/Merge)

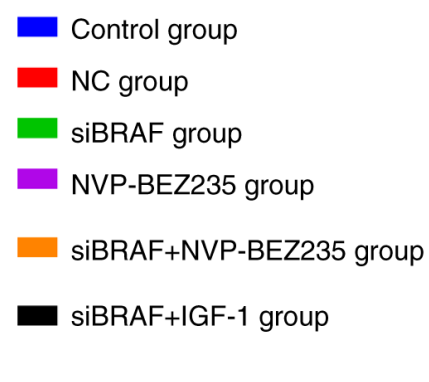

Figure 4. Comparison of the cell apoptosis rate in each group after transfection by TUNEL assay. (A) The apoptosis of cancer cells in each group under light microscope (x200). (B) The apoptosis rate of cancer cells in each group expressed as the percentage of apoptotic cells (\%). The data were measured and expressed as the mean \pm standard deviation. The comparison between the two groups was performed by unpaired t-test, and the comparison between multiple groups was performed by one-way ANOVA. The cell experiment was repeated three times. ${ }^{*} \mathrm{P}<0.05$, compared with the control group and NC group, revealing statistical difference; ${ }^{\prime} \mathrm{P}<0.05$, compared with the siBRAF + NVP-BEZ235 group, showing statistical difference. NC, negative control; si, small interfering.

(all $\mathrm{P}<0.05)$. Furthermore, compared with the NC group, the mRNA expression of PI3K, Akt and mTOR was decreased, while PTEN expression was increased in the siBRAF group, NVP-BEZ235 group and siBRAF + NVP-BEZ235 group, and especially evident in the siBRAF + NVP-BEZ235 group than that in the siBRAF group and NVP-BEZ235 group, with significant differences (all $\mathrm{P}<0.05)$. However, in the siBRAF + IGF-1 group, the mRNA expression of PI3K, Akt and mTOR was increased, while PTEN was decreased when compared with the siBRAF + NVP-BEZ235 group, and the difference was significant (all $\mathrm{P}<0.05$ ). There was no obvious difference between the siBRAF group and NVP-BEZ235 group, and between NC group and siBRAF + IGF-1 group (all P $>0.05$ ) (Fig. 7).

Comparison of the protein expression levels in each group after transfection. Compared with the control group, no obvious difference was revealed in BRAF protein expression between the NC group and NVP-BEZ235 group ( $\mathrm{P}>0.05)$. In addition, it was evidently decreased in siBRAF group, siBRAF + NVP-BEZ235 group and siBRAF + IGF-1 group, with statistical difference (all $\mathrm{P}<0.05$ ).

Compared with the control group, there was no significant difference in the protein expression levels of PTEN, PI3K,
p-PI3K,Akt,p-Akt,mTOR,p-mTOR,ERCC1 and BRCA1,Bax, and $\mathrm{Bcl}-2$ in the $\mathrm{NC}$ group (all $\mathrm{P}>0.05$ ). The protein expression levels of PI3K, p-PI3K, Akt, p-Akt, mTOR, p-mTOR, ERCC1, BRCA1 and Bcl-2 were decreased, while those of PTEN and Bax were increased in the siBRAF group, NVP-BEZ235 group, and siBRAF + NVP-BEZ235 group, and especially evident in the siBRAF + NVP-BEZ235 group than that in the siBRAF group and NVP-BEZ235 group, with statistical difference (all $\mathrm{P}<0.05$ ). In addition, the protein expression levels of PI3K, p-PI3K, Akt, p-Akt, mTOR, p-mTOR, ERCC1 and BRCA1 and Bcl-2 were increased in siBRAF + IGF-1 group, but those of PTEN and Bax were decreased when compared with the siBRAF + NVP-BEZ235 group $(\mathrm{P}<0.05)$. No significant difference in the detected protein expression levels was revealed between the siBRAF group and NVP-BEZ235 group, and between the NC group and siBRAF + IGF-1 group (all $\mathrm{P}>0.05$ ) (Fig. 8).

\section{Discussion}

Surgery, radiotherapy and chemotherapy are the major methods used for the treatment of lung cancer (26). However, the overall survival outcome of lung cancer patients is not satisfactory after comprehensive treatment (27). The causes of recurrence, 
A

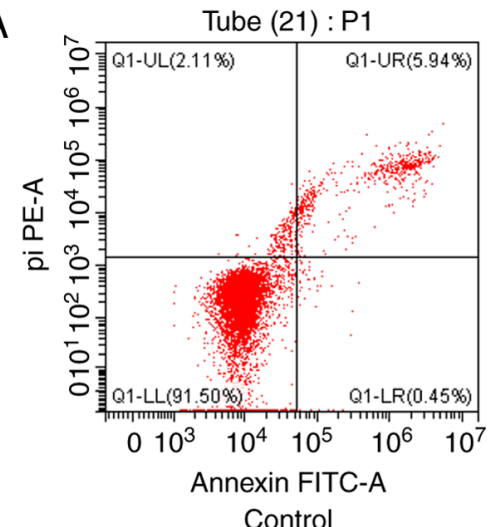

Tube-A-1082: P1

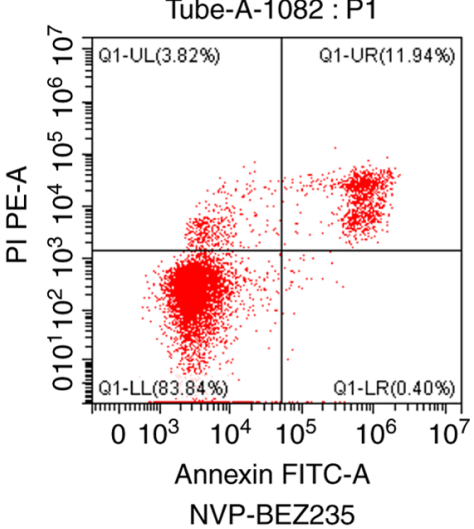

B
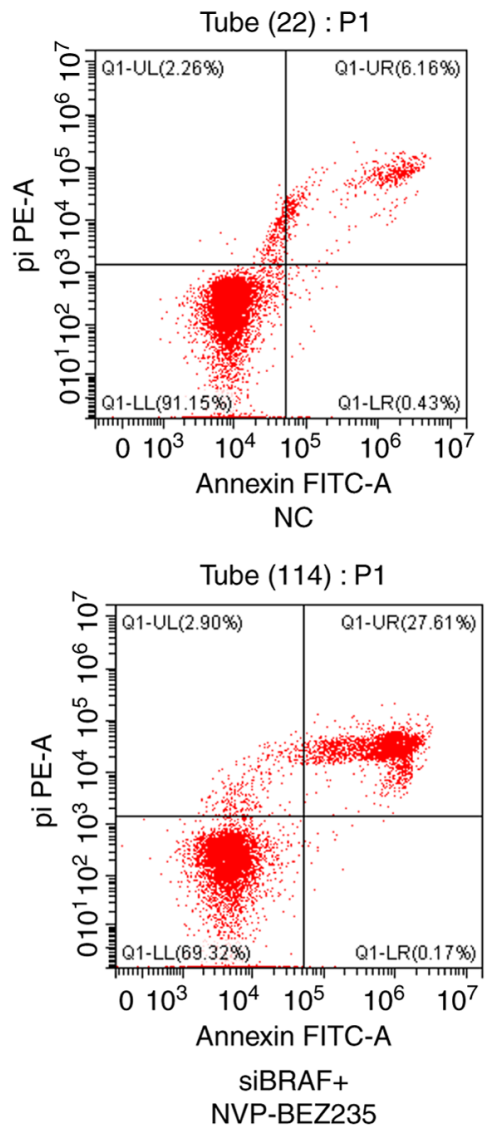

Tube-A-1078:P1
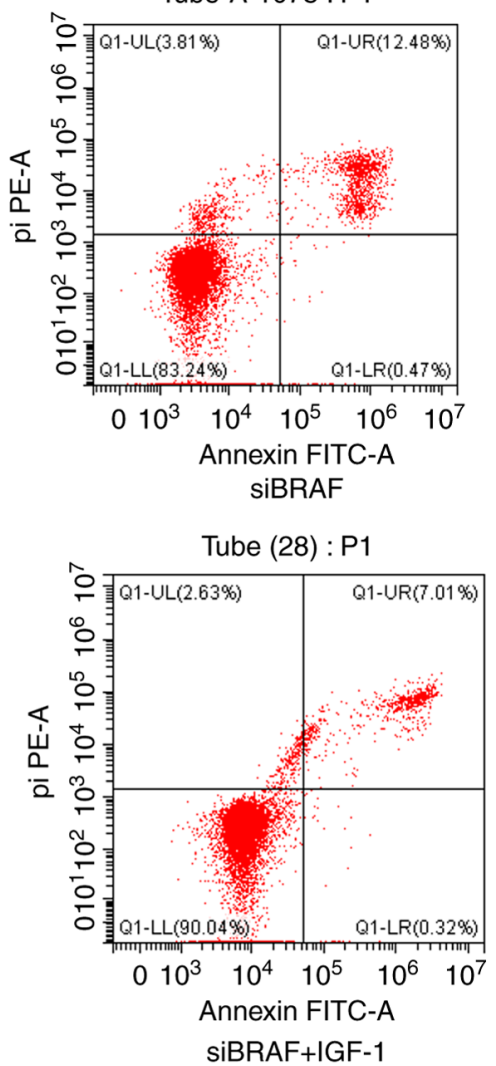

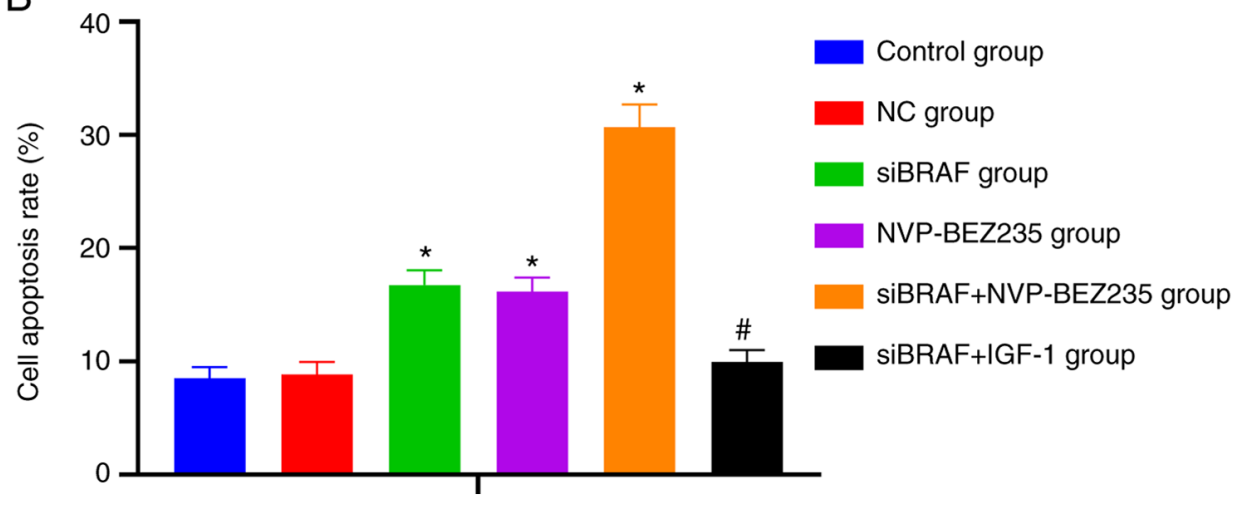

Figure 5. Comparison of the cell apoptosis rate in each group after transfection by flow cytometry using Annexin V-PI staining. (A) The apoptosis of cancer cells in each group. (B) The apoptosis rate of cancer cells in each group expressed as the percentage (\%). The data were measured and expressed by mean \pm standard deviation. The comparison between the two groups was performed by unpaired t-test, and the comparison between multiple groups was performed by one-way ANOVA. The cell experiment was repeated three times. ${ }^{*} \mathrm{P}<0.05$, comparison with the control group and NC group, revealing statistical difference; ${ }^{\text {P }}<0.05$, comparison with siBRAF + NVP-BEZ235 group, showing statistical difference. NC, negative control; si, small interfering.

metastasis and treatment resistance after comprehensive treatment are not quite clear at present. In addition, there are a small number of cell sub-populations that are resistant to various therapies in tumor tissue, which can survive after traditional chemotherapy or chemotherapy, and continue to proliferate, forming new recurrence or metastasis (28). In other words, chemotherapy can kill most sensitive cells, but not all cells. Notably, BRAF is a proto-oncogene found in numerous tumor types, which can be regulated and used as a clinical strategy to overcome or prevent acquired drug resistance in colorectal cancer and also reported in lung cancer $(29,30)$.

Prior studies have confirmed that the PI3K/Akt/mTOR signaling pathway can regulate the growth, proliferation and invasion of tumor cells from numerous aspects (31). For instance, PI3K can activate cell cycle-dependent protein kinases to promote cells to enter the $S$ phase and induce DNA synthesis (32). In addition, the pathway can also affect cell apoptosis through a number of ways (33). It can promote the transcription of anti-apoptotic proteins by activating NF-kB, and inhibit caspase-mediated apoptosis by phosphorylation to suppress pro-apoptotic proteins (34). In addition, activated Akt can activate endothelial NO synthetase, promote endothelial cell migration and form new blood vessels (35). Furthermore, concerning its role in stimulating cell adhesion and migration, activated Akt can increase the activity of NF-kB, promote cell movement and increase invasiveness by increasing MMP-2 


\section{A}

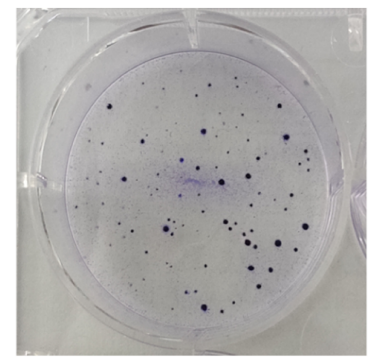

$0.5 \mu \mathrm{l}$

Control

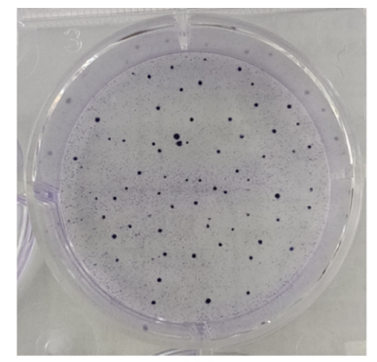

NC

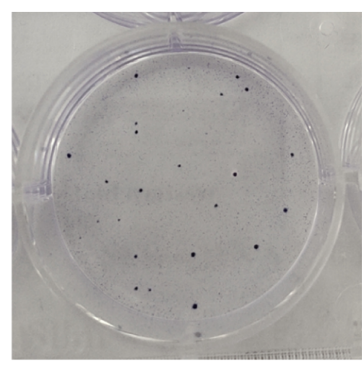

SiBRAF
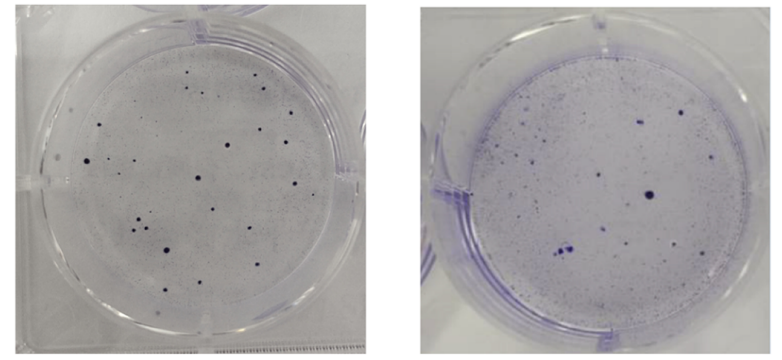

SiBRAF+

NVP-BEZ235

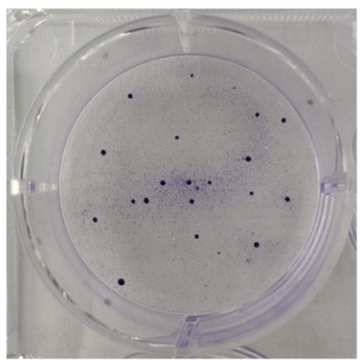

Control

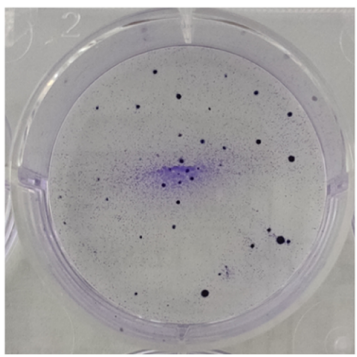

NC

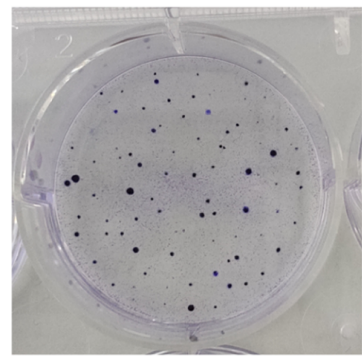

SiBRAF+lGF-1

$3 \mu \mathrm{l}$

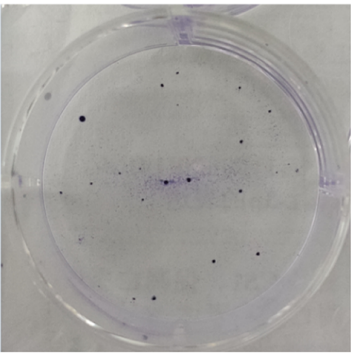

NVP-BEZ235

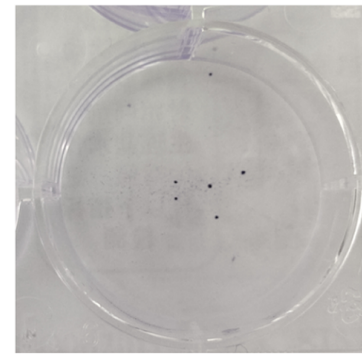

SiBRAF+

NVP-BEZ235

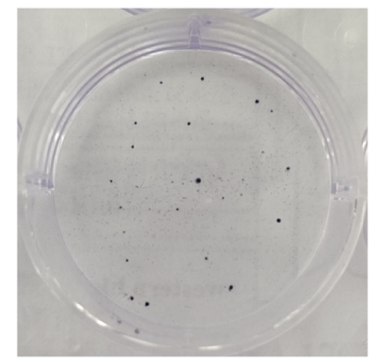

SiBRAF

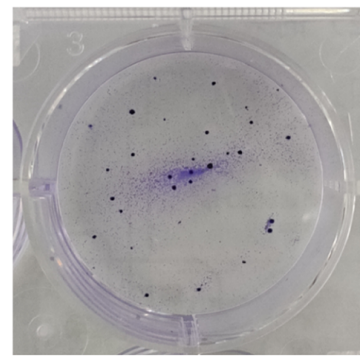

siBRAF+IGF-1

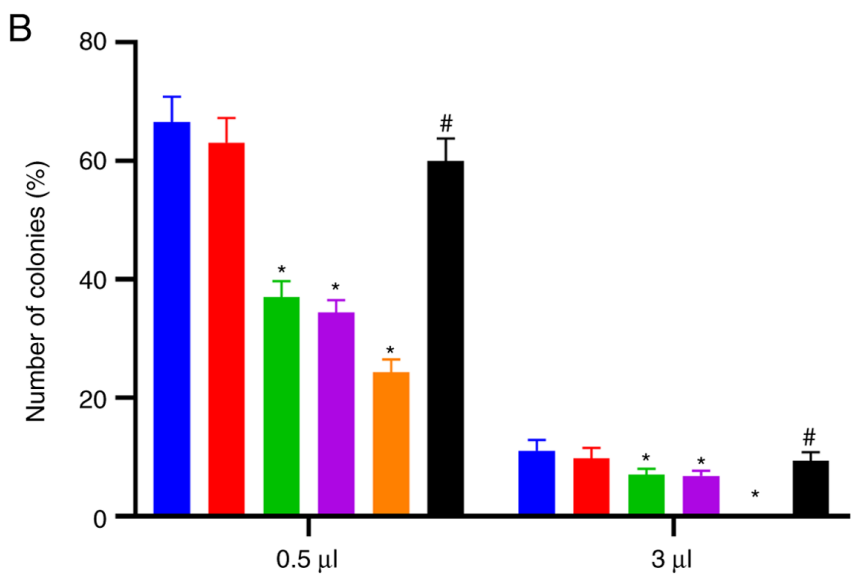

Control group

NC group

siBRAF group

NVP-BEZ235 group

siBRAF+NVP-BEZ235 group

siBRAF+IGF-1 group

Figure 6. Comparison of the colony-forming number of cells of each group after transfection. (A) The experimental images of colony formation in each group. (B) Histogram of the number of colony-forming cells in each group expressed as the (\%). The data were measured and expressed as the mean \pm standard deviation. The comparison between the two groups was performed by unpaired t-test, and the comparison between multiple groups was performed by one-way ANOVA. The cell experiment was repeated three times. " $\mathrm{P}<0.05$, compared with the control group and $\mathrm{NC}$ group, revealing statistical difference; ${ }^{"} \mathrm{P}<0.05$, compared with the siBRAF + NVP-BEZ235 group, showing statistical difference. NC, negative control; si, small interfering. 


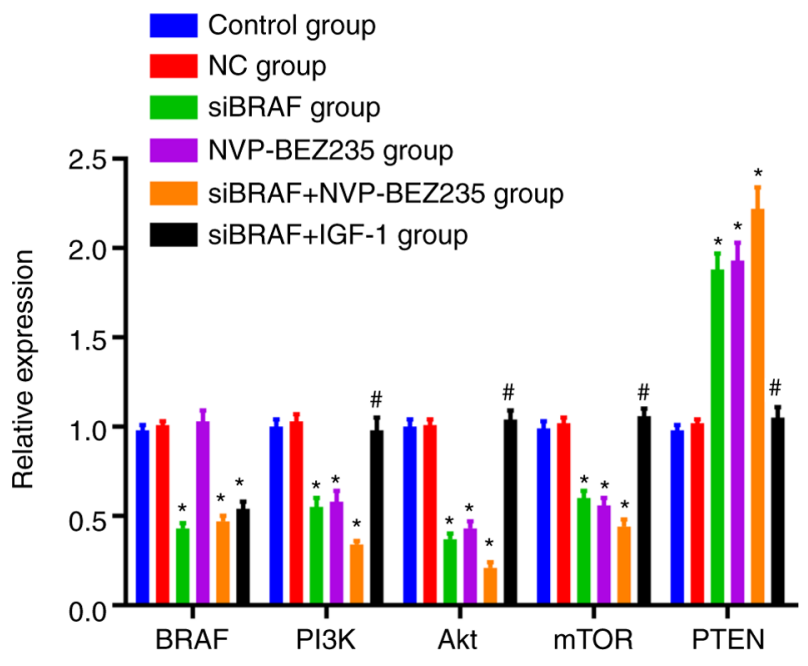

Figure 7. Comparison of the mRNA expression levels of BRAF, PI3K, Akt, mTOR and PTEN in each group after transfection by reverse transcription-quantitative PCR. The data were measured and expressed as the mean \pm standard deviation. The comparison between the two groups was performed by unpaired t-test, and the comparison between multiple groups was performed by one-way ANOVA. The cell experiment was repeated three times. $\mathrm{P}<0.05$, compared with the control group and $\mathrm{NC}$ group, revealing statistical difference; ${ }^{\prime} \mathrm{P}<0.05$, compared with the siBRAF + NVP-BEZ235 group, showing statistical difference. NC, negative control; si, small interfering.

and MMP-9 levels that are critical in extracellular matrix degradation (36). Notably, there have been various studies concerning the role of PI3K/Akt/mTOR involved in cancer development and resistance to chemotherapy, and downregulation of AKT or inhibited activation of the PI3K/Akt/mTOR signaling pathway could be an available beneficial adjuvant antitumor therapy $(37,38)$. In addition, it has been reported that targeting the PI3K/AKT/mTOR pathway can be a potential option for lung cancer treatment, which embodies preventing oncogenesis and regulating chemotherapy response $(39,40)$.

The PI3K/Akt/mTOR signal is involved in the regulation of cell proliferation and differentiation by activating PI3K, Akt and mTOR, which can affect cell activity, cycle, cell growth and cell proliferation (41). In addition, BRAF is generally highly expressed in different tumor cells to modulate cell growth, differentiation and apoptosis, which can stimulate the occurrence of tumors in the case of aberrant cell metabolism resulted from abnormal activation of relevant pathways due to increased expression of BRAF (42). In the present study, NSCLC cells were divided into different groups with different transfection protocols. According to the results, with the detection of BRAF expression in different groups, verifying the expression status of BRAF and side validation of successful transfection, it was revealed that BRAF gene silencing and PI3K inhibitor NVP-BEZ235 treatment separately resulted in obvious decreased cell viability at 2-6 days, decreased migration ability, shortened proportion of $\mathrm{S}$ phase, increased proportion of $\mathrm{G}_{1} / \mathrm{G}_{0}$ phase, increased apoptosis rate, and decreased number of colony formation. The two separate treatments also had decreased mRNA expression of PI3K, Akt and mTOR, increased PTEN mRNA expression, decreased protein expression levels of PI3K, p-PI3K, Akt, p-Akt, mTOR, p-mTOR, ERCC1, BRCA1 and Bcl-2, and increased protein expression levels of PTEN and Bax. In particular, the beneficial roles were further enhanced with a combined treatment of BRAF gene silencing and PI3K inhibitor, which in turn highlighted the synergistic effect of the combination of siBRAF and NVP-BEZ235.

It is theorized that BRAF can promote the expression of p-Akt and mTOR (mammalian target of rapamycin) through phosphorylation of PI3K, which can increase the level of $\mathrm{Bcl}-2$, decrease the level of Bax and enhance the metabolism of cells; concurrently, when PI3K inhibitor was administered and BRAF expression was silenced, the phosphorylation of Akt induced by BRAF was blocked, and the response of tumor cells to BRAF was decreased, thus inhibiting tumor growth and migration and promoting tumor cell apoptosis. In addition to the effect on the phosphorylated levels of PI3K, Akt and mTOR, total expression levels of PI3K, Akt and the downstream protein $\mathrm{mTOR}$ were also suppressed after silencing of BRAF gene expression, which may be related to the translation efficiency of selective mRNAs after protein modification. It suggests that BRAF gene silencing has a role in mediating the activation of the PI3K/Akt/mTOR signaling pathway, which is considered to be realized through the inhibition of both the total and phosphorylated protein levels of PI3K, Akt and mTOR. Concurrently, in the present study, the activation of the PI3K/Akt/mTOR signaling pathway, the increase of expression of chemoresistance-related enzymes and the increase of S-phase cell subsets all suggested a reduced sensitivity to chemotherapeutic drugs. In addition, the change of the cell cycle also reduced the sensitivity of the remaining cells to chemotherapy. Thus, these cells that remained after chemotherapy were resistant to chemotherapy, which may be the main reason for the failure of local treatment after chemotherapy. In this way, the PI3K/Akt/mTOR signaling pathway inhibitor, dual inhibitor of PI3K and mTOR, could block BRAF-mediated cell proliferation and survival, indicating that the PI3K/Akt/mTOR signaling pathway may promote the inhibition of cell response to BRAF. Accordingly, BRAF may be involved in cell proliferation and survival as an upstream factor of the PI3K/Akt/mTOR signaling pathway. Notably, the $\mathrm{PI} 3 \mathrm{~K} / \mathrm{Akt} / \mathrm{mTOR}$ signaling pathway agonist (PI3K agonist) was used in the in the present study, and an opposite trend was revealed under the combined treatment of BRAF gene silencing and the PI3K agonist, highlighting that activation of PI3K/Akt/mTOR reversed the positive role of BRAF gene silencing, and demonstrated the role of BRAF gene expression silencing in inhibiting the activation of PI3K/Akt/mTOR in the development of NSCLS.

In addition, it should be noted that cisplatin, as a classical drug for chemotherapy, is mainly involved in DNA synthesis as a competitive inhibitor in the $S$ phase (43). For example, a previous in vitro study revealed that combined use of cisplatin could block the G1/S phase of the cell cycle of colorectal cancer cells in a certain concentration range (44). Additionally, when HeLa hepatoma cells were treated with cisplatin using different methods, it was revealed that cisplatin alone decreased cell viability, glycolysis and oxidative phosphorylation (45). In the present study, after cell treatment with cisplatin, the cell cycle was analyzed by flow cytometry, and it was found that BRAF gene silencing, the pathway inhibitor and their combined treatment decreased the proportion of cells 

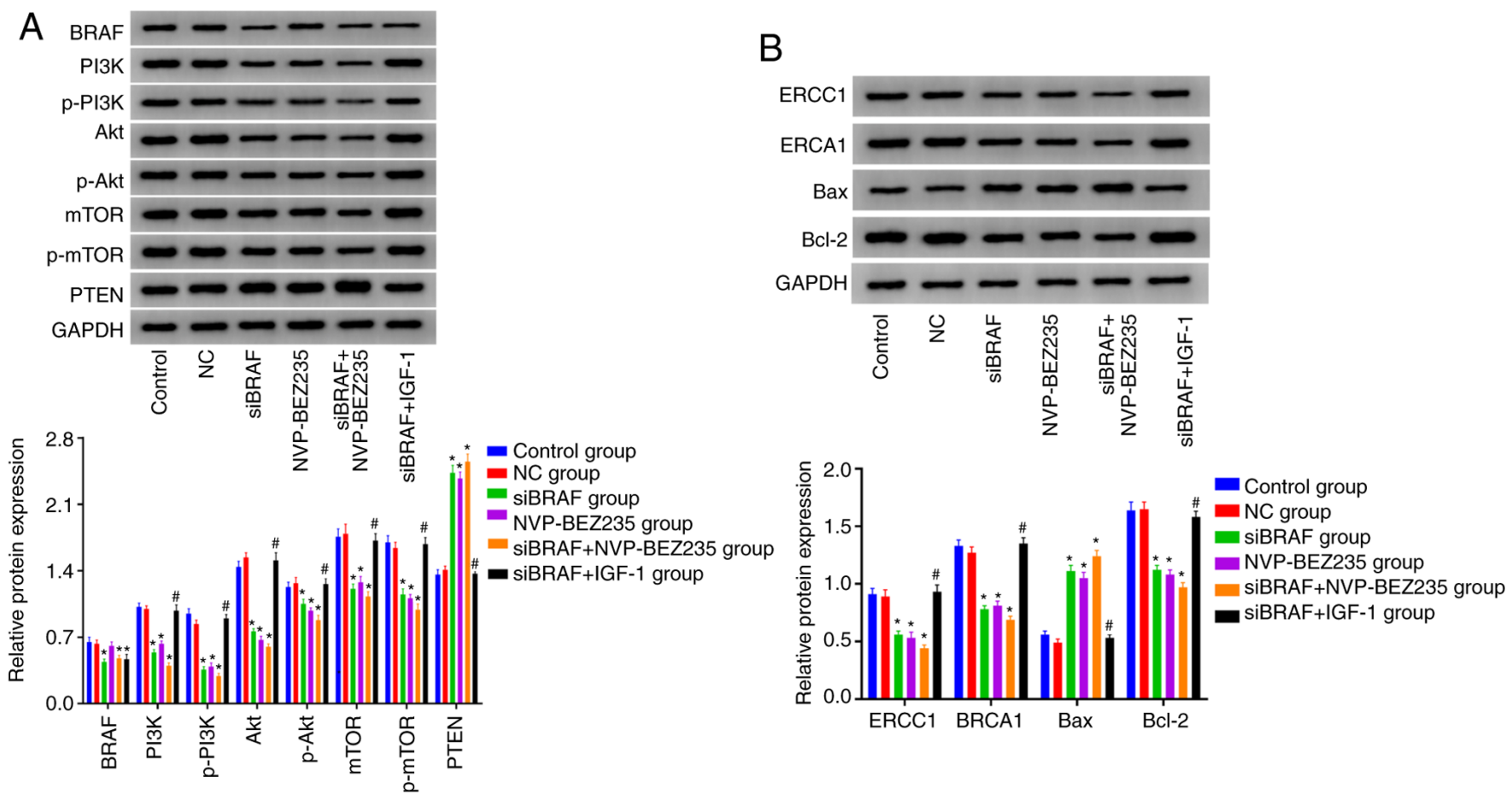

Figure 8. Detection of the protein expression levels of BRAF, PI3K, p-PI3K, Akt, p-Akt, mTOR, p-mTOR, PTEN, ERCC1 and BRCA1, Bax, and Bcl-2 in each group after transfection by western blotting. (A) Western blotting bands and statistical analysis of protein expression including BRAF and PI3K/Akt/mTOR signaling pathway-related proteins. (B) Western blotting bands and statistical analysis of the protein expression including cisplatin resistance-related enzymes and apoptotic proteins. The data were measured and expressed as the mean \pm standard deviation. The comparison between the two groups was performed by unpaired t-test, and the comparison between multiple groups was performed by one-way ANOVA. The cell experiment was repeated three times. "P $<0.05$, compared with the control group and $\mathrm{NC}$ group, revealing statistical difference; ${ }^{~} \mathrm{P}<0.05$, compared with the siBRAF + NVP-BEZ235 group, showing statistical difference. p-, phosphorylated; NC, negative control; si, small interfering.

in the $\mathrm{S}$ phase and $\mathrm{G}_{2} / \mathrm{M}$ phase, and increased the proportion of $G_{1} / G_{0}$-phase cells, and was especially significant under the combined action; while the pathway agonist reversed the positive role of BRAF gene silencing, and blocked A549/DDP cells in the $S$ phase and $\mathrm{G}_{2} / \mathrm{M}$ phase. The sensitivity of cells to chemotherapy is different depending on the phase of the cell cycle, and is higher in the $G_{1} / G_{0}$ phase than that in the $\mathrm{G}_{2} / \mathrm{M}$ phase and $\mathrm{S}$ phase (46), however the specific mechanism is not clear. Therefore, theoretically, the use of chemotherapy drugs to render cells sensitive to the cell cycle during chemotherapy, or in other words, reduce the proportion of $\mathrm{G}_{2} / \mathrm{M}$-phase and S-phase cells but increase the proportion of $\mathrm{G}_{1} / \mathrm{G}_{0}$ phase can improve the sensitivity of chemotherapy (47). In the present study, MTT and cell colony experiments were used to evaluate chemosensitivity, which was revealed to be decreased in cells treated with chemotherapeutics to various doses. The possible reason may be that cells with stem cell characteristics are enriched after treatment of chemotherapy agents, and the proportion of S-phase cells increased, resulting in the decrease of sensitivity to chemotherapy. Silencing of the BRAF gene may inhibit the activation of the PI3K/Akt/mTOR signaling pathway to reduce the expression of chemoresistance-related enzymes and partially restore the sensitivity of A549/DDP cells to chemotherapy drugs, thus increasing the tolerance of tumor cells to treatment. In addition, suppressing the activation of this signaling pathway can induce an increase in cell subsets of the S-phase, thus increasing the resistance of cells to chemotherapy. After blocking the pathway by silencing of BRAF and using pathway inhibitor NVP-BEZ235, the proportion of S-phase cell subsets was reduced, and the sensitivity to chemotherapy was partially restored, which in turn supports our prior hypothesis of the role of the PI3K/Akt $/ \mathrm{mTOR}$ signaling pathway mediated by BRAF gene silencing. The role of regulating PI3K/AKT/mTOR pathway in lung cancer has been demonstrated previously (48). In a similar mechanism of action, it has been reported that an antitumor effect could be promoted with the suppression of PI3K and p-Akt protein expression, which may be achieved through the regulation of the PI3K/AKT pathway achieved by targeting the EGFR gene through miRNA-223 (49), supporting the antitumor effect of using PI3K inhibitor to suppress the proposed pathway in NSCLC. Similarly, Wang et al also reported a similar regulatory axis of gene-signaling pathway in NSCLC, and found that ELF3 could promote cell growth and metastasis by regulating PI3K/Akt and ERK pathways in NSCLC (50), highlighting the role of searching for potential genes as promising new targets to inhibit the PI3K/Akt/mTOR signaling pathway for the treatment of NSCLC patients. To sum up, silencing of BRAF gene expression and inhibiting the activation of the PI3K/Akt/mTOR signaling pathway could decrease cell viability, inhibit the cell cycle and migration, increase the apoptosis rate, decrease the number of colony-forming cells and increase chemosensitivity of NSCLC. The present study suggests that BRAF gene silencing combined with NVP-BEZ235 exert a synergistic effect to reduce the resistance of cells to chemotherapy and improve the sensitivity of chemotherapy by suppressing the activation of the PI3K/Akt/mTOR signaling pathway. In addition, activation of the PI3K/Akt/mTOR signaling pathway may reverse the role of silencing of BRAF gene expression in cell viability, the cell 
cycle and migration, apoptosis, and colony formation, providing a potential approach for improving the chemosensitivity of NSCLC. However, our study still has some limitations. For example, there was a weak additive effect of siBRAF + NVP vs. siBRAF alone, as indicated in the detection of the protein expression levels of related indexes in each group after transfection by western blotting, which deserves to be verified by further experimentation. In addition, the present study was a single-cell experiment, and the reliability of the findings in this study can be enhanced by an animal experiment. However, the present study, for the first time, clarified the possible mechanism of NSCLC cell biological characteristics and chemosensitivity using a siRNA silencing technique, with abundant experimental data to support the positive role of BRAF gene silencing and inhibited the PI3K/Akt/mTOR signaling pathway thus suppressing the progression and enhancing chemosensitivity of NSCLC. It may provide a potential reference for suppressing tumor aggravation and improving the therapeutic outcomes of NSCLC at the genetic level.

\section{Acknowledgements}

Not applicable.

\section{Funding}

No funding was received.

\section{Availability of data and materials}

The datasets used and/or analyzed during the current study are available from the corresponding author on reasonable request.

\section{Authors' contributions}

BR made substantial contributions to conception and design, acquisition of data, analysis and interpretation of data; was involved in drafting the manuscript and revising it critically for important intellectual content; and gave final approval of the version to be published. HL and YY helped with general data collection and analysis. YL helped with statistical analysis. All authors have participated sufficiently in the work to take public responsibility for appropriate portions of the content; and agreed to be accountable for all aspects of the work in ensuring that questions related to the accuracy and integrity of the work are appropriately investigated and resolved. All authors read and approved the final manuscript.

\section{Ethics approval and consent to participate}

Not applicable.

\section{Patient consent for publication}

Not applicable.

\section{Competing interests}

The authors declare that they have no competing interests.

\section{References}

1. Masel EK, Berghoff AS, Füreder LM, Heicappell P, Schlieter F, Widhalm G, Gatterbauer B, Dieckmann U, Birner P, Bartsch R, et al: Decreased body mass index is associated with impaired survival in lung cancer patients with brain metastases: A retrospective analysis of 624 patients. Eur J Cancer Care (Engl) 26: e12707, 2017.

2. Sui T, Liu A and Jiao W: Difference of lung function retention after segmentectomy and lobectomy. Zhongguo Fei Ai Za Zhi 22: 178-182, 2019.

3. Wang W, Zhang L, Liu L, Zheng Y, Zhang Y, Yang S, Shi R and Wang S: Chemosensitizing effect of shRNA-mediated ERCC1 silencing on a Xuanwei lung adenocarcinoma cell line and its clinical significance. Oncol Rep 37: 1989-1997, 2017.

4. Levy A, Faivre-Finn C, Hasan B, De Maio E, Berghoff AS, Girard N, Greillier L, Lantuéjoul S, O'Brien M, Reck M, et al: Diversity of brain metastases screening and management in non-small cell lung cancer in Europe: Results of the European Organisation for Research and Treatment of Cancer Lung Cancer Group survey. Eur J Cancer 93: 37-46, 2018.

5. Majem M, Juan O, Insa A, Reguart N, Trigo JM, Carcereny E, García-Campelo R, García Y, Guirado M and Provencio M: SEOM clinical guidelines for the treatment of non-small cell lung cancer (2018). Clin Transl Oncol 21: 3-17, 2019.

6. Cheng L, Gao E, Zhu F, Wang Y, Zhong J and An T: A case report on successful third challenge to the Pemetrexed-based regimen for advanced non-small cell lung cancer. Zhongguo Fei Ai Za Zhi 22: 395-400, 2019.

7. Zhang Y: Chemotherapy in advanced non-small cell lung cancer: Present and future. J Int Transl Med 5: 38-44, 2017.

8. Matsufuji H, Shiozaki E, Nakatake Y, Yoshida K, Kamada K and Matsuo T: A case of slowly progressive brain metastasis with minor bleeding after removal of and chemotherapy for non-small cell lung cancer. No Shinkei Geka 45: 339-344, 2017.

9. Farré PL, Scalise GD, Duca RB, Dalton GN, Massillo C, Porretti J, Graña K, Gardner K, De Luca P and De Siervi A: CTBP1 and metabolic syndrome induce an mRNA and miRNA expression profile critical for breast cancer progression and metastasis. Oncotarget 9: 13848-13858, 2018.

10. Zhang L, Wang Y, Rashid MH, Liu M, Angara K, Mivechi NF, Maihle NJ, Arbab AS and Ko L: Malignant pericytes expressing GT198 give rise to tumor cells through angiogenesis. Oncotarget 8: 51591-51607, 2017.

11. Glentis A, Oertle P, Mariani P, Chikina A, El Marjou F, Attieh Y, Zaccarini F, Lae M, Loew D, Dingli F, et al: Cancer-associated fibroblasts induce metalloprotease-independent cancer cell invasion of the basement membrane. Nat Commun 8: 924, 2017.

12. Oudin MJ and Weaver VM: Physical and chemical gradients in the tumor microenvironment regulate tumor cell invasion, migration, and metastasis. Cold Spring Harb Symp Quant Biol 81: 189-205, 2016

13. Shen Y, Su C, Shi Y, Liu X and Zhao L: Chitosan nanoparticles promoted cancer cell invasion and metastasis via the massive production of reactive oxygen species. J Biomater Tissue Eng 7: 484-490. 2017.

14. Li N, Gao WJ and Liu NS: LncRNA BCAR4 promotes proliferation, invasion and metastasis of non-small cell lung cancer cells by affecting epithelial-mesenchymal transition. Eur Rev Med Pharmacol Sci 21: 2075-2086, 2017.

15. Shimizu T, Asakuma M, Tomioka A, Inoue Y, Hirokawa F, Hayashi M and Uchiyama K: Span-1 and CA19-9 as predictors of early recurrence and lymph node metastasis for patients with invasive pancreatic cancer after pancreatectomy. Am Surg 84: 109-113, 2018.

16. Zhu BP, Guo ZQ, Lin L and Liu Q: Serum BSP, PSADT, and Spondin-2 levels in prostate cancer and the diagnostic significance of their ROC curves in bone metastasis. Eur Rev Med Pharmacol Sci 21: 61-67, 2017.

17. Feng HM, Zhao Y, Zhang JP, Zhang JH, Jiang P, Li B and Wang C: Expression and potential mechanism of metabolism-related genes and CRLS1 in non-small cell lung cancer. Oncol Lett 15: 2661-2668, 2018.

18. Choi H, Ding CG, Lee SB, Durrans A, Ryu S, Elemento O, Wong S, Altorki NK and Mittal V: Abstract 1159: A novel HGF-MET paracrine signaling pathway promotes growth and resistance to chemotherapy in lung cancer. Cancer Res 74: 1159,2014 
19. Bahrami A, Hasanzadeh M, Hassanian SM, ShahidSales S, Ghayour-Mobarhan M, Ferns GA and Avan A: The potential value of the $\mathrm{PI} 3 \mathrm{~K} / \mathrm{Akt} / \mathrm{mTOR}$ signaling pathway for assessing prognosis in cervical cancer and as a target for therapy. J Cell Biochem 118: 4163-4169, 2017

20. Pan JH, Wang HB, Du XF, Liu JY and Zhang DJ: Polydatin induces human cervical cancer cell apoptosis via PI3K/AKT/mTOR signaling pathway. Zhongguo Zhong Yao Za Zhi 42: 2345-2349, 2017.

21. Du C, Zhang T, Xiao X, Shi Y, Duan H and Ren Y: Protease-Activated Receptor-2 promotes kidney tubular epithelial inflammation by inhibiting autophagy via the PI3K/Akt/mTOR signalling pathway. Biochem J 474: 2733-2747, 2017.

22. Tian B, Zhao Y, Liang T, Ye X, Li Z, Yan D, Fu Q and Li Y: Curcumin inhibits urothelial tumor development by suppressing IGF2 and IGF2-mediated PI3K/AKT/mTOR signaling pathway. J Drug Target 25: 626-636, 2017.

23. Liu M, Tang R and Jiang Y: Pantoprazole induces apoptosis of leukemic cells by inhibiting expression of P-Glycoprotein/Multidrug Resistance-Associated Protein-1 Through PI3K/AKT/mTOR Signaling. Indian J Hematol Blood Transfus 33: 500-508, 2017

24. Dalal AA, Guerin A, Mutebi A and Culver KW: Economic analysis of BRAF gene mutation testing in real world practice using claims data: Costs of single gene versus panel tests in patients with lung cancer. J Med Econ 21: 649-655, 2018.

25. Livak KJ and Schmittgen TD: Analysis of relative gene expression data using real-time quantitative PCR and the 2(-Delta Delta C(T)) method. Methods 25: 402-408, 2001.

26. Toffart AC, Duruisseaux M, Brichon PY, Pirvu A, Villa J, Selek L, Guillem P, Dumas I, Ferrer L, Levra MG and Moro-Sibilot D: Operation and chemotherapy: Prognostic factors for lung cancer with one synchronous metastasis. Ann Thorac Surg 105: 957-965, 2018.

27. Wang X, Zhang W, Du W, Zhang X, Ren X and Cao S: Efficacy and survival analysis of apatinib in patients with advanced nonsquamous non-small cell lung cancer after failure of first-line treatment. Zhongguo Fei Ai Za Zhi 20: 761-768, 2017.

28. Farnie G, Sotgia F and Lisanti MP: High mitochondrial mass identifies a sub-population of stem-like cancer cells that are chemo-resistant. Oncotarget 6: 30472-30486, 2015.

29. Corcoran RB, Dias-Santagata D, Bergethon K, Iafrate AJ, Settleman J and Engelman JA: BRAF gene amplification can promote acquired resistance to MEK inhibitors in cancer cells Harboring the BRAF V600E Mutation. Ence Signaling 3: ra84 2010.

30. Ohashi K, Sequist LV, Arcila ME, Moran T, Chmielecki J, Lin YL, Pan Y, Wang L, de Stanchina E, Shien K, et al: Lung cancers with acquired resistance to EGFR inhibitors occasionally harbor BRAF gene mutations but lack mutations in KRAS, NRAS, or MEK1. Proc Natl Acad, USA 109: 109: E2127-E2133, 2012.

31. Xiao W, Tang H, Wu M, Liao Y, Li K, Li L and Xu X: Ozone oil promotes wound healing by increasing the migration of fibroblasts via PI3K/Akt/mTOR signaling pathway. Biosci Rep 37: BSR20170658, 2017.

32. Okada K, Nogami A, Ishida S, Akiyama H, Chen C, Umezawa Y and Miura O: FLT3-ITD induces expression of Pim kinases through STAT5 to confer resistance to the PI3K/Akt pathway inhibitors on leukemic cells by enhancing the mTORC1/Mcl-1 pathway. Oncotarget 9: 8870-8886, 2017.

33. Fu JH, Yang S, Nan CJ, Zhou CC, Lu DQ, Li S and Mu HQ: miR-182 affects renal cancer cell proliferation, apoptosis, and invasion by regulating PI3K/AKT/mTOR signaling pathway. Eur Rev Med Pharmacol Sci 24: 7202, 2020.

34. Guoyin Z, Hao P, Min L, Wei G, Zhe C and Changquan L: Antihepatocarcinoma effect of Portulaca oleracea L. in Mice by $\mathrm{PI} 3 \mathrm{~K} / \mathrm{Akt} / \mathrm{mTOR}$ and Nrf2/HO-1/NF-кB Pathway. Evid Based Complement Alternat Med 2017: 8231358, 2017.

35. Kim GD: Myricetin inhibits angiogenesis by inducing apoptosis and suppressing PI3K/Akt/mTOR signaling in endothelial cells. J Cancer Prev 22: 219-227, 2017.
36. Chen J, Crawford R and Xiao Y: Vertical inhibition of the PI3K/Akt/mTOR pathway for the treatment of osteoarthritis. J Cell Biochem 114: 245-249, 2013.

37. Burris HA III: Overcoming acquired resistance to anticancer therapy: Focus on the PI3K/AKT/mTOR pathway. Cancer Chemother Pharmacol 71: 829-842, 2013.

38. Zhang HY, Zhang PN and Sun H: Aberration of the PI3K/AKT/mTOR signaling in epithelial ovarian cancer and its implication in cisplatin-based chemotherapy. Eur J Obstet Gynecol Reprod Biol 146: 81-86, 2009.

39. Cheng H, Shcherba M, Pendurti G, Liang Y, Piperdi B and Perez-Soler R: Targeting the PI3K/AKT/mTOR pathway: Potential for lung cancer treatment. Lung Cancer Manag 3: 67-75, 2014.

40. Xu JL, Wang ZW, Hu LM, Yin ZQ, Huang MD, Hu ZB, Shen HB and Shu YQ: Genetic Variants in the PI3K/PTEN/AKT/mTOR pathway predict Platinum-based chemotherapy response of advanced non-small cell lung cancers in a Chinese population. Asian Pac J Cancer Prev 13: 2157-2162, 2012.

41. Zhang Q, Lai S, Hou X, Cao W, Zhang Y and Zhang Z: Protective effects of PI3K/Akt signal pathway induced cell autophagy in rat knee joint cartilage injury. Am J Transl Res 10: 762-770, 2018.

42. Cheriyan VT, Alsaab H, Sekhar S, Venkatesh J, Mondal A, Vhora I, Sau S, Muthu M, Polin LA, Levi E, et al: A CARP-1 functional mimetic compound is synergistic with BRAF-targeting in non-small cell lung cancers. Oncotarget 9: 29680-29697, 2018.

43. Oei AL, van Leeuwen CM, Ahire VR, Rodermond HM, Ten Cate R, Westermann AM, Stalpers LJA, Crezee J, Kok HP, Krawczyk PM, et al: Enhancing synthetic lethality of PARP-inhibitor and cisplatin in BRCA-proficient Tumour cells with hyperthermia. Oncotarget 8: 28116-28124, 2017.

44. An SH, Kang JH, Kim DH and Lee MS: Vitamin C increases the apoptosis via up-regulation p53 during cisplatin treatment in human colon cancer cells. BMB Rep 44: 211-216, 2011.

45. Heymann PGB, Henkenius KSE, Ziebart T, Braun A, Hirthammer K, Halling F, Neff A and Mandic R: Modulation of tumor cell metabolism by laser photochemotherapy with cisplatin or zoledronic acid in vitro. Anticancer Res 38: 1291-1301, 2018.

46. Nolte E, Wach S, Silva IT, Lukat S, Ekici AB, Munkert J, Müller-Uri F, Kreis W, Oliveira Simões CM, Vera J, et al: A new semisynthetic cardenolide analog 3 $\beta$-[2-(1-amantadine)-1on-ethylamine]-digitoxigenin (AMANTADIG) affects G2/M cell cycle arrest and miRNA expression profiles and enhances proapoptotic survivin-2B expression in renal cell carcinoma cell lines. Oncotarget 8: 11676-11691, 2017.

47. Xu C, Sun G, Yuan G, Wang R and Sun X: Effects of Platycodin D on proliferation, apoptosis and PI3K/Akt Signal Pathway of Human Glioma U251 Cells. Molecules 19: 21411-21423, 2014

48. Li H, Hu J, Wu S, Wang L, Cao X, Zhang X, Dai B, Cao M, Shao R, Zhang R, et al: Auranofin-mediated inhibition of $\mathrm{PI} 3 \mathrm{~K} / \mathrm{AKT} / \mathrm{mTOR}$ axis and anticancer activity in non-small cell lung cancer cells. Oncotarget 7: 3548-3558, 2016.

49. Ma HP, Kong WX, Li XY, Li W, Zhang Y and Wu Y: miRNA-223 is an anticancer gene in human non-small cell lung cancer through the PI3K/AKT pathway by targeting EGFR. Oncol Rep 41: 1549-1559, 2019.

50. Wang H, Yu Z, Huo S, Chen Z, Ou Z, Mai J, Ding S and Zhang J: Overexpression of ELF3 facilitates cell growth and metastasis through PI3K/Akt and ERK signaling pathways in non-small cell lung cancer. Int J Biochem Cell Biol 94: 98-106, 2018.

This work is licensed under a Creative Commons Attribution-NonCommercial-NoDerivatives 4.0 International (CC BY-NC-ND 4.0) License. 